\title{
Advanced Control of a Continuous Solution Copolymerization Process
}

\author{
Nádson Murilo Nascimento Lima, ${ }^{1}$ Lamia Zuñiga Liñan, ${ }^{1}$ Flavio Manenti, ${ }^{2}$ \\ Rubens Maciel Filho, ${ }^{1}$ Marcelo Embiruçu, ${ }^{3}$ and Maria Regina Wolf Maciel $^{1}$ \\ ${ }^{1}$ Department of Chemical Processes, Faculty of Chemical Engineering, State University of Campinas (UNICAMP), \\ University City, P.O. Box 6066, 13081-970 Campinas, SP, Brazil \\ ${ }^{2}$ CMIC Department "Giulio Natta"-Politecnico di Milano, Piazza Leonardo da Vinci 32, 20133 Milano, Italy \\ ${ }^{3}$ Industrial Engineering Programme, Polytechnique Institute, Federal University of Bahia (UFBA), Federação, \\ 40210-630 Salvador, BA, Brazil
}

Correspondence should be addressed to Nádson Murilo Nascimento Lima, nadson@feq.unicamp.br

Received 14 March 2011; Accepted 15 May 2011

Academic Editor: Moshe Sheintuch

Copyright (C) 2011 Nádson Murilo Nascimento Lima et al. This is an open access article distributed under the Creative Commons Attribution License, which permits unrestricted use, distribution, and reproduction in any medium, provided the original work is properly cited.

\begin{abstract}
A model-based predictive control system is designed for a copolymerization reactor. These processes typically have such a high nonlinear dynamic behavior to make practically ineffective the conventional control techniques, still so widespread in process and polymer industries. A predictive controller is adopted in this work, given the success this family of controllers is having in many chemical processes and oil refineries, especially due to their possibility of including bounds on both manipulated and controlled variables. The solution copolymerization of methyl methacrylate with vinyl acetate in a continuous stirred tank reactor is considered as an industrial case study for the analysis of the predictive control robustness in the field of petrochemical and polymer production. Both regulatory and servo problems scenarios are considered to check tangible benefits deriving from modelbased predictive controller implementation.
\end{abstract}

\section{Introduction}

Operations management of polymerization plants is quite complex, since such processes are characterized by strong nonlinearities, intense state variable interactions, and wide variations in operating conditions. Beyond these issues that are strictly related to the physical process, it is worth underlining that the field of polymer production, and generally speaking petrochemical plants, is undergoing more and more reduced net profit margins and frequent market dynamics, both making the operations management of production sites a problematic issue. Controlling polymer reactors and related operations has always been a challenging task even accounting for the fact that operators rely on conventional methods to do it, rather than model-based methodologies. This is mainly attributed to the lack for rigorous/detailed process knowledge, reliable kinetic models, and online measures of some specific properties of the final product.
Thanks to the increased computing power and the spread of detailed process modeling and programming tools, the use of rigorous models for generating accurate system predictions and for making use of predictive control methodologies is nowadays feasible for many processes. It is not a coincidence that many techniques based on rigorous models have emerged. The one that has become very popular in recent years is model predictive control (MPC).

MPC has been the most successful advanced control technique applied in the process industries. Its formulation naturally handles timedelays, multivariable interactions, and constraints [2-5]. The name MPC arises from use an explicit prediction model of the process to be controlled so as to foresee its future behavior. Such a capacity of predicting process behavior can be exploited to get the so-called online optimal control, where tracking error, that is, the difference between the predicted output and the desired reference trajectory, is minimized over a future horizon. For this reason, MPC 


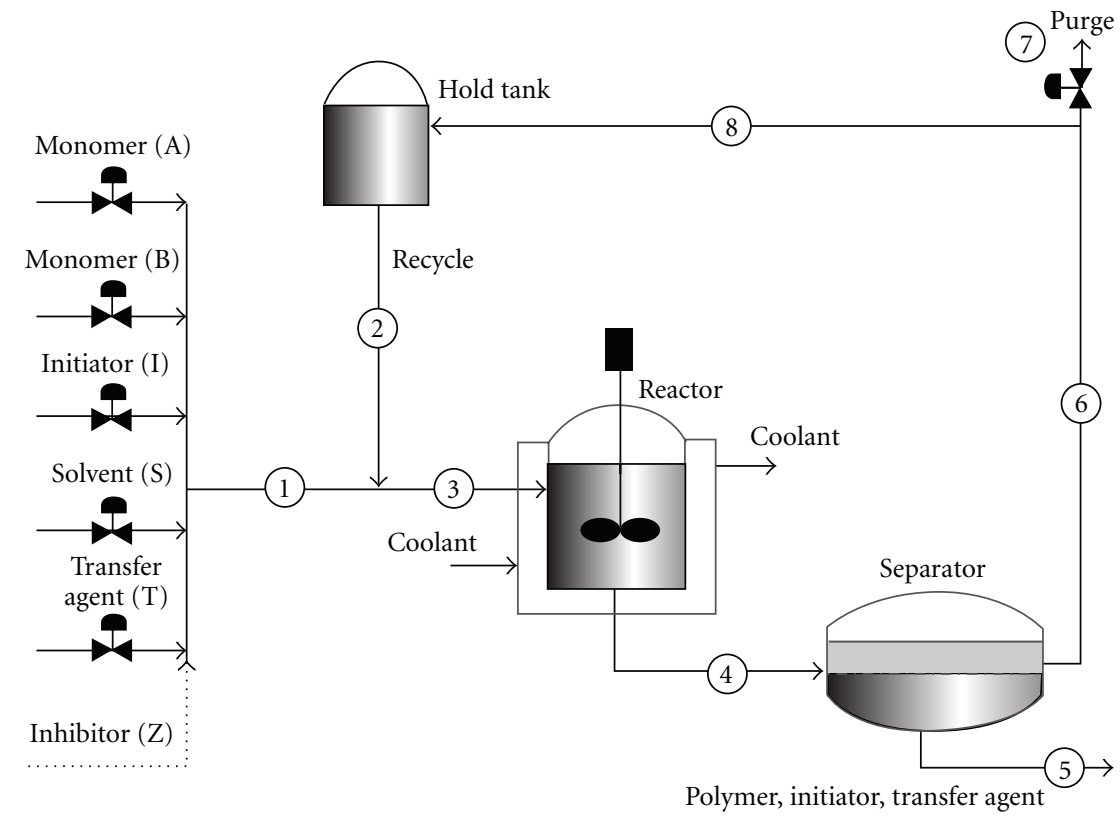

FIgURE 1: Basic process configuration [1].

strategy is also known as moving horizon control or receding horizon control, where the horizon which the output variable is predicted on is moved in a sampling instant in the direction of the future, each sampling instant.

MPC benefits have been validated on polymerization reactors [6-9] by providing good results (i.e., satisfactory tracking performance, robustness, ability to suppress disturbances, and accuracy under real-time constraints) without significantly increasing computational complexity and effort [10-15]. Some recent works also deal with stability and faulttolerant design issues [16-18].

One of the well-known MPC algorithms is dynamic matrix control (DMC), originally developed by Cutler and Ramaker [19] and rigorously derived for linear systems [20]. A DMC procedure uses the system information in the context of an optimizer that solves the control problem for the trajectory of the manipulated variable over a future time horizon based on a dynamic model of the process. DMC basic ideas are [21] the following:

(1) use a linear model to predict future deviations from a set point over a prediction horizon forming a quadratic objective function to be minimized,

(2) adjust a control horizon of manipulated input moves,

(3) implement the first move and measure the resulting output at the next sample time,

(4) update the model and loop to (1).

The condition of the DMC in employing a linear model and a quadratic objective function results in a convex optimization problem easily solved by means of quadratic programming. There is a good deal of literature focusing on the application of DMC in polymerization processes. Peterson et al. [22] developed a control algorithm that uses an explicit nonlinear process model and the basic elements of the classical DMC and applied it to a semibatch polymerization reactor. Gobin et al. [23] applied a DMC algorithm to the polymerization of styrene in the presence of a binary initiator mixture, involving a cascade of two continuous stirredtank reactors (CSTRs). Meziou et al. [24] have performed a simulation study to assess the performance of DMC for an ethylene-propylene-diene polymerization reactor. Yüce et al. [25] have investigated experimentally and by simulation the dynamic matrix control of a batch solution polymerization reactor. Lima [26] developed and implemented a DMC algorithm for a copolymerization process in a well-mixed jacketed tank reactor.

In this study, the application of DMC is investigated for a copolymerization reactor in solution to control the polymer production rate, the copolymer composition, the molecular weight, and the reactor temperature. Four monovariable control loops are designed and analyzed separately; multivariable strategies will be accounted for in future developments. The copolymerization of methyl methacrylate with vinyl acetate is considered as a case study. A nonlinear dynamic model of the system is used to simulate both regulatory and servo responses of DMC.

\section{Dynamic Matrix Control}

Dynamic matrix control (DMC) was developed at Shell Oil Company in 1979 [19]. The basic idea is to use a timedomain step-response model (called convolution model) of the process to calculate the future changes in the manipulated variable that will minimize a given performance index. In the DMC approach, we would like to have the $\mathrm{PH}$ (prediction horizon) future output responses matching some "optimum" trajectory by finding the "best" values of the $\mathrm{CH}$ (control 


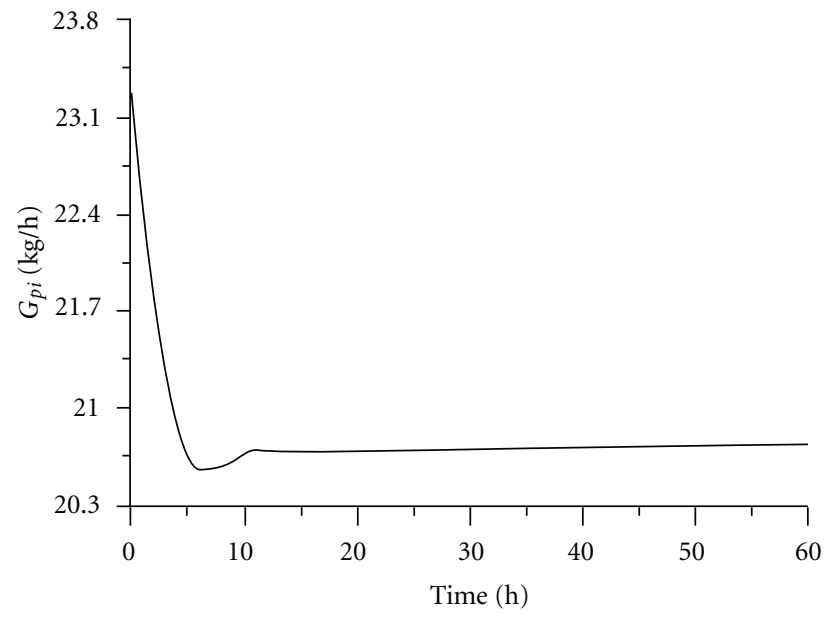

(a)

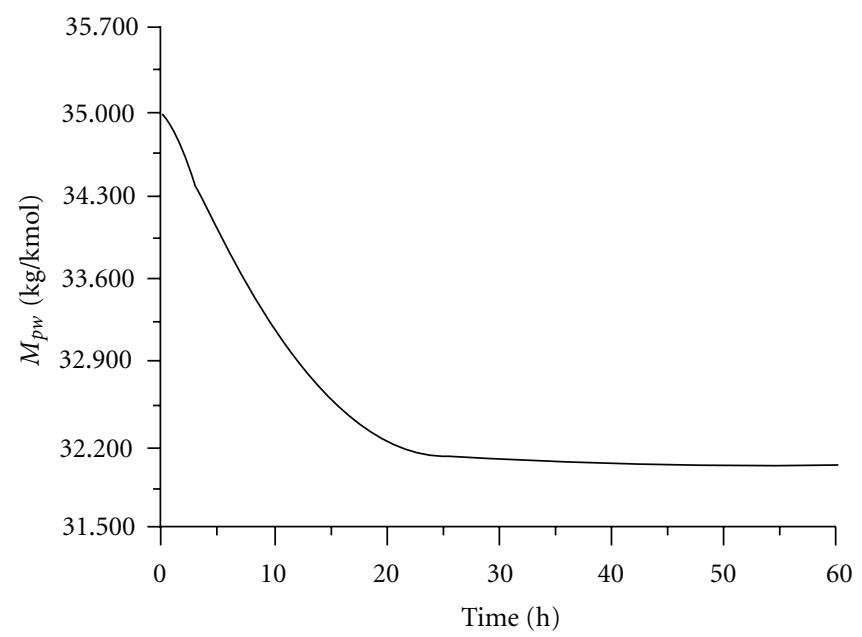

(c)

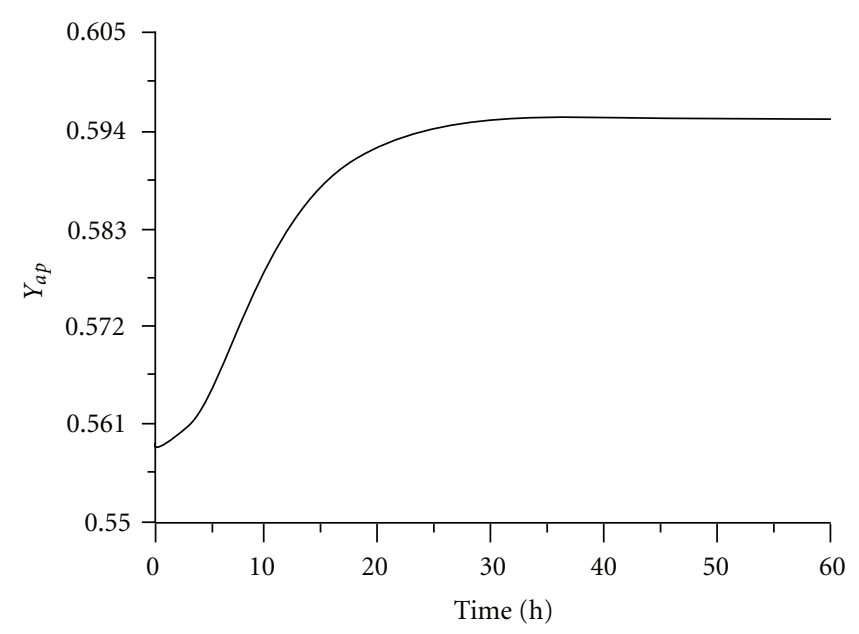

(b)

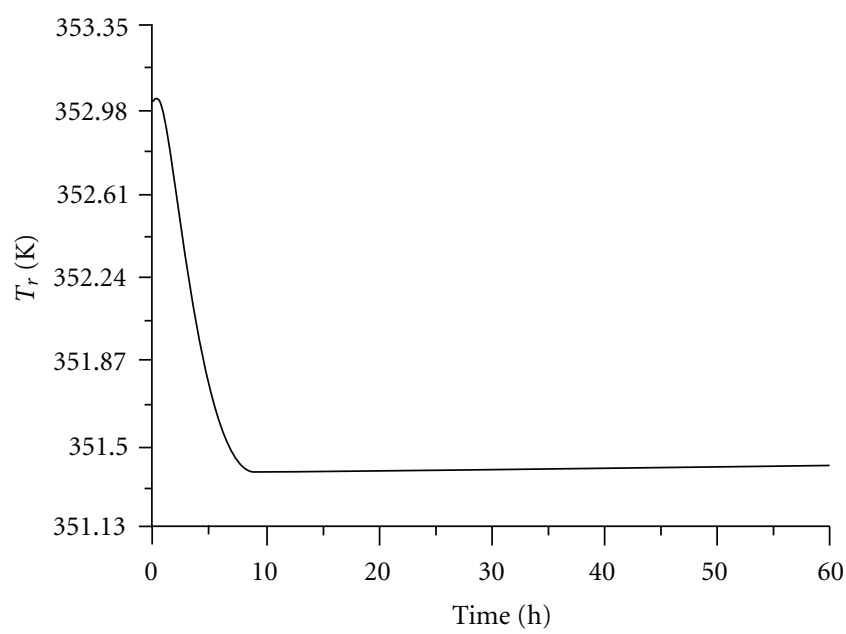

(d)

Figure 2: Open-loop simulation to inhibitor disturbance.

horizon) future changes in the manipulated variables. This is exactly the concept of a least-squares problem of fitting the $\mathrm{PH}$ data points with an equation having $\mathrm{CH}$ coefficients. This is a valid least-squares problem as long as the $\mathrm{PH}$ is greater than the $\mathrm{CH}$.

The aim of a predictive control law is to drive future outputs close to the reference trajectory. The computation sequence is first to calculate the reference trajectory and estimate the output predictions using the convolution model. Then, the errors between predicted and reference trajectories are calculated [27]. The next step is to estimate the sequence of the future controls by the minimization of an appropriate quadratic objective function $J$. However, only the first predicted control action is really implemented. At this point, the data vectors are shifted so that the calculations can be repeated at the next sample instant. This function $J$ is defined by:

$$
J=\sum_{i=1}^{\mathrm{PH}}\left(y_{i}^{d}-y_{\mathrm{CL}, i}^{\mathrm{pred}}\right)^{2}+f^{2} \cdot \sum_{k=1}^{\mathrm{CH}}\left[\left(\Delta u_{k}\right)^{\mathrm{future}}\right]^{2},
$$

where $i$ and $k$ are the time interval, $y$ is the output variable (controlled variable), $u$ is the input variable (manipulated variable), with $\Delta u_{k}=u_{k}-u_{k-1}$, and $f$ is the suppression factor for the movements of the manipulated variable. This control parameter assures that no drastic control action is calculated. A too small $f$ results in large control actions, which can result in an instable response, while a too large $f$ results in a slow response. Thus, $f$ is even a weighting factor for the movements of the manipulated variable.

In the original form of DMC strategy, the term $y_{i}^{d}$ is the set point. In the present work, to prevent drastic control actions, a term is introduced based on Model Algorithmic Control strategy [28]. The desired output is calculated through an optimal trajectory defined by a first-class filter:

$$
y_{i}^{d}=\alpha \cdot y_{i-1}^{\text {actual }}+(1-\alpha) \cdot y_{i-1}^{\text {set }},
$$

where $y_{i-1}^{\text {actual }}$ is the vector of the current measured value of the controlled variable at the sampling time $i-1, y_{i-1}^{\text {set }}$ is the vector of the set point of the controlled variable at the 


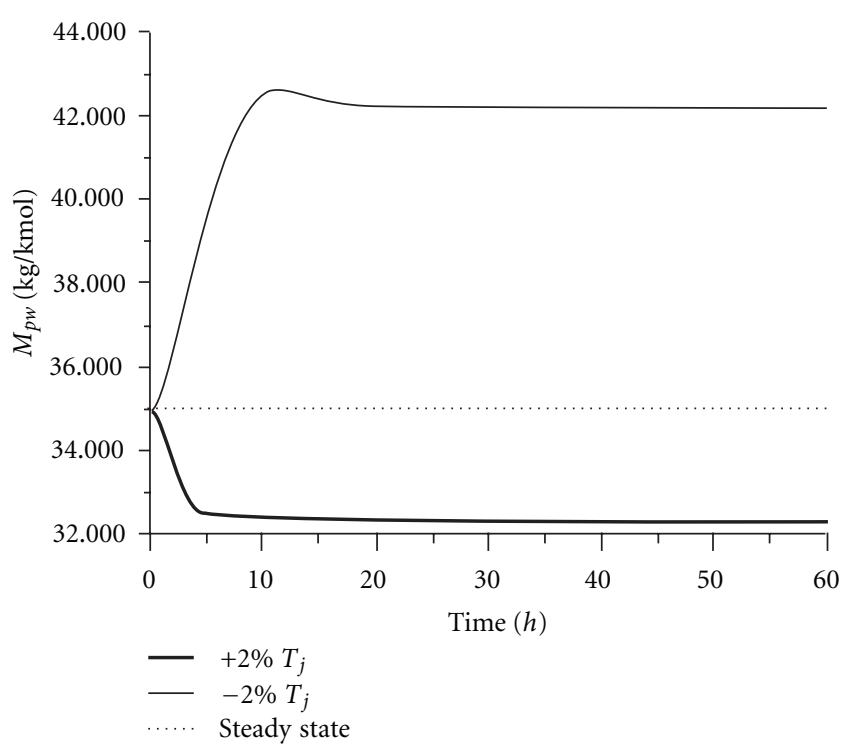

Figure 3: Nonlinear behavior of the weight average molecular weight $\left(M_{p w}\right)$ when symmetric disturbances of $\pm 2 \%$ in the reactor jacket temperature $\left(T_{j}\right)$ occur.

TABLE 1: Steady-state operating conditions.

\begin{tabular}{lc}
\hline Inputs & \\
Monomer A (MMA) feed rate & $G_{a f}=18 \mathrm{~kg} / \mathrm{h}$ \\
Monomer B (VAc) feed rate & $G_{b f}=90 \mathrm{~kg} / \mathrm{h}$ \\
Initiator (AIBN) feed rate & $G_{i f}=0.18 \mathrm{~kg} / \mathrm{h}$ \\
Solvent (benzene) feed rate & $G_{s f}=36 \mathrm{~kg} / \mathrm{h}$ \\
Chain transfer (acetaldehyde) feed rate & $G_{t f}=2.7 \mathrm{~kg} / \mathrm{h}$ \\
Inhibitor (m-DNB) feed rate & $G_{z f}=0$ \\
Reactor jacket temperature & $T_{j}=336.15 \mathrm{~K}$ \\
Reactor feed temperature & $T_{r f}=353.15 \mathrm{~K}$ \\
Purge ratio & $\xi=0.05$ \\
Reactor parameters & \\
Reactor volume & $V_{r}=1 \mathrm{~m}^{3}$ \\
Reactor heat transfer area & $S_{r}=4.6 \mathrm{~m}^{2}$ \\
Outputs & \\
Copolymer production rate & $G_{p i}=23.3 \mathrm{~kg} / \mathrm{h}$ \\
Mole fraction of A in copolymer & $Y_{a p}=0.559$ \\
Average molecular weight & $M_{p w}=34,995 \mathrm{~kg} / \mathrm{kmol}$ \\
Reactor temperature & $T_{r}=353.02 \mathrm{~K}$ \\
\hline
\end{tabular}

sampling time $i-1$, and $\alpha$ is the reference trajectory parameter, with $0 \leq \alpha \leq 1$.

Predicted values $y_{\mathrm{CL}, i}^{\mathrm{pred}}$ in (1) can be obtained directly from a model of the process. However, since this model is never perfect because of unavoidably ideal assumptions and simplifications, the controller will be not sufficiently robust $[8,9]$. Therefore, the following correction is applied:

$$
y_{\mathrm{CL}, i}^{\mathrm{pred}}=y_{\mathrm{CL}, i}+\left(y_{i-1}^{\mathrm{actual}}-y_{\mathrm{CL}, i-1}\right) \text {, }
$$

where $y_{\mathrm{CL}, i}$ is defined by a convolution model. It is considered that the difference between the predicted and actual values in
TABLE 2: SISO control loops.

\begin{tabular}{lcc}
\hline Loop & Manipulated variable & Controlled variable \\
\hline 1 & Reactor jacket temperature & Copolymer production rate \\
& $\left(T_{j}\right)$ & $\left(G_{p i}\right)$ \\
2 & Monomers A/B feed rate & Mole fraction of A in \\
& $\left(G_{a f} / G_{b f}\right)$ & copolymer $\left(Y_{a p}\right)$ \\
3 & Reactor jacket temperature & Weight average molecular \\
& $\left(T_{j}\right)$ & weight $\left(M_{p w}\right)$ \\
4 & Reactor jacket temperature & Reactor temperature $\left(T_{r}\right)$ \\
\hline
\end{tabular}

TABLE 3: Parameters of the DMC to the regulatory problem.

\begin{tabular}{lcccc}
\hline Parameters & Loop 1 & Loop 2 & Loop 3 & Loop 4 \\
\hline Convolution horizon & 48 & 111 & 26 & 4 \\
Prediction horizon $(\mathrm{PH})$ & 2 & 5 & 9 & 2 \\
Control horizon $(\mathrm{CH})$ & 1 & 1 & 1 & 1 \\
$\begin{array}{l}\text { Suppression factor }(f) \\
\text { Reference trajectory }\end{array}$ & 0.001 & 0.003 & 1.500 & 0.001 \\
parameter $(\alpha)$ & 0.002 & 0.001 & 0.010 & 0.001 \\
Sampling time $(\mathrm{h})$ & 0.25 & 0.25 & 0.25 & 0.25 \\
IAE* & 6.946 & 0.121 & 23,803 & 1.744 \\
\hline
\end{tabular}

*IAE units: loop 1 (kg/h), loop $2(-)$, loop $3(\mathrm{~kg} / \mathrm{kmol})$, and loop $4(\mathrm{~K})$.

TABLE 4: Parameters of the DMC to the servo problem.

\begin{tabular}{lcccc}
\hline Parameters & Loop 1 & Loop 2 & Loop 3 & Loop 4 \\
\hline Convolution horizon & 48 & 111 & 26 & 4 \\
Prediction horizon $(\mathrm{PH})$ & 2 & 5 & 9 & 2 \\
Control horizon $(\mathrm{CH})$ & 1 & 1 & 1 & 1 \\
Suppression factor $(f)$ & 1.500 & 2.500 & 4.000 & 2.000 \\
Reference trajectory & 0.002 & 0.001 & 0.010 & 0.001 \\
parameter $(\alpha)$ & 0.25 & 0.25 & 0.25 & 0.25 \\
Sampling time $(\mathrm{h})$ & 99.245 & 11.976 & 209,180 & 365.420 \\
IAE* & *IAE units: loop 1 (kg/h), loop 2(-), loop 3 (kg/kmol), loop 4 (K).
\end{tabular}

TABLE 5: Sensitivity analysis parameters of DMC for regulatory problem.

\begin{tabular}{lcccc}
\hline Parameters & Loop 1 & Loop 2 & Loop 3 & Loop 4 \\
\hline Convolution horizon & 48 & 111 & 26 & 8 \\
Prediction horizon $(\mathrm{PH})^{*}$ & 2 & 5 & 9 & 2 \\
Control horizon $(\mathrm{CH})$ & 1 & 1 & 1 & 1 \\
Suppression factor $(f)^{* *}$ & 0.001 & 0.003 & 1.500 & 0.001 \\
Reference trajectory parameter $(\alpha)$ & 0.002 & 0.001 & 0.010 & 0.001 \\
Sampling time $(\mathrm{h})$ & 0.25 & 0.25 & 0.25 & 0.25 \\
\hline
\end{tabular}

*Value for changes on the $f$.

**Value for changes on the PH.

the previous instant is valid for the current instant. Thus, the system reaches the desired value after successive corrections. Details on DMC and on obtaining the convolution model are given by Luyben [29]. 


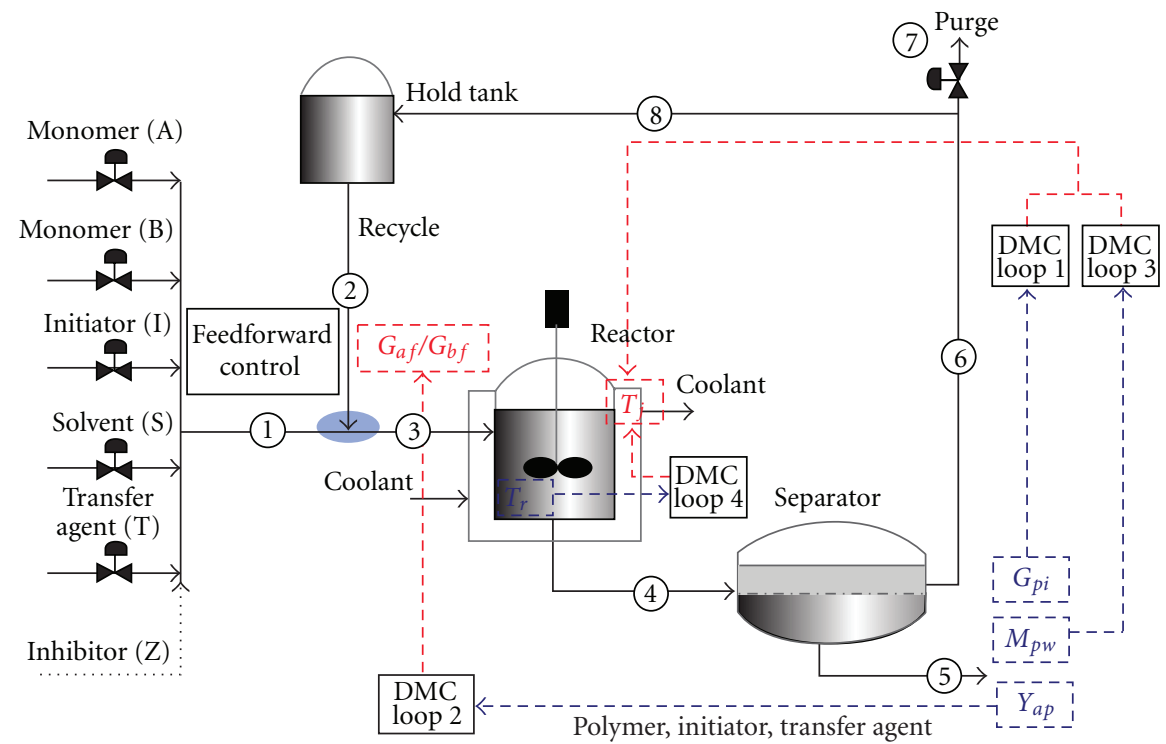

FIGURE 4: Schematic representation of the controllers evaluated.

TABLE 6: Sensitivity analysis parameters of DMC for servo problem.

\begin{tabular}{lc}
\hline Parameters & Loop 3 \\
\hline Convolution horizon & 26 \\
Prediction horizon $(\mathrm{PH})$ & $9^{*}$ \\
Control horizon $(\mathrm{CH})$ & 1 \\
Suppression factor $(f)$ & $4.000^{* *}$ \\
Reference trajectory parameter $(\alpha)$ & 0.001 \\
Sampling time $(\mathrm{h})$ & 0.25 \\
\hline
\end{tabular}

*Value for changes on the $f$.

**Value for changes on the $\mathrm{PH}$.

The controller tuning is carried out through the Integral of the Absolute value of the Error (IAE), defined by (4), looking up the best combination of parameters $(\mathrm{PH}, \mathrm{CH}$, $f, \alpha)$ that minimizes this performance criterion. Therefore, the following optimization problem is solved during tuning procedures:

$$
\begin{aligned}
\min _{\mathrm{PH}, \mathrm{CH}, f, \alpha}[J(\mathrm{PH}, \mathrm{CH}, f, \alpha) \\
\left.\quad=\mathrm{IAE}=\int_{t_{0}}^{t_{f}}\left|y^{\text {set }}(t)-y^{\text {actual }}(t)\right| \cdot d t\right] .
\end{aligned}
$$

In (4), $t_{0}$ and $t_{f}$ are the initial and final times, respectively, of the evaluation period.

\section{Case Study: Copolymerization of MethylMethacrylate with Vinyl Acetate}

The process considered in this paper is the solution copolymerization of methyl methacrylate with vinyl acetate within a continuous stirred tank reactor [1]. Figure 1 is a qualitative process flow diagram of a copolymerization reactor including the recycle loop (streams 6,8 , and 2). Monomer $A$ is methyl methacrylate, monomer B is vinyl acetate, the solvent is benzene, the initiator is azobisisobutyronitrile (AIBN), and the chain transfer agent is acetaldehyde. The monomer stream may also contain inhibitors such as m-dinitrobenzene (m-DNB).

Monomers A and B are continuously added with initiator, solvent, and chain transfer agent. In addition, an inhibitor may enter with the fresh feeds as an impurity. Feed streams (stream 1) are mixed to the recycle stream (stream 2 ) to give the reactor inlet flowrate (stream 3 ). The reactor is assumed to be a jacketed well-mixed tank. A coolant flows through the jacket to remove heat generated during the copolymerization process. Polymer, solvent, unreacted monomers, initiator, and chain transfer agent flow out of the reactor (stream 4) to enter the separator. Here, polymer is ideally separated (stream 5). Residual initiator and chain transfer agent are also removed in this step. In a real process, the separation process is particularly complex, as it often involves a series of steps, which may include dryers and distillation columns. We assume also unreacted monomers and solvent (stream 6) are recycled upstream, accounting for purge line only (stream 7), which represents vent and other losses. Purge line is required to prevent any accumulation of inerts within the system. After the purge, the monomers and solvent (stream 8) are stored in the recycle hold tank, which acts as a surge capacity to smooth out variations in the recycle flow and composition. The effluent (stream 2) recycle is then added to the fresh feeds.

The important reactor output variables to control polymer quality are the polymer production rate $\left(G_{p i}\right)$, the mole fraction of monomer $\mathrm{A}$ in the copolymer $\left(Y_{a p}\right)$, the weight average molecular weight $\left(M_{p w}\right)$, and the reactor temperature $\left(T_{r}\right)$. Inputs are the reactor flows of monomer A $\left(G_{a f}\right)$, monomer B $\left(G_{b f}\right)$, initiator $\left(G_{i f}\right)$, chain transfer agent $\left(G_{t f}\right)$, solvent $\left(G_{s f}\right)$, inhibitor $\left(G_{z f}\right)$, the reactor jacket temperature $\left(T_{j}\right)$, and the reactor feed temperature $\left(T_{r f}\right)$. 


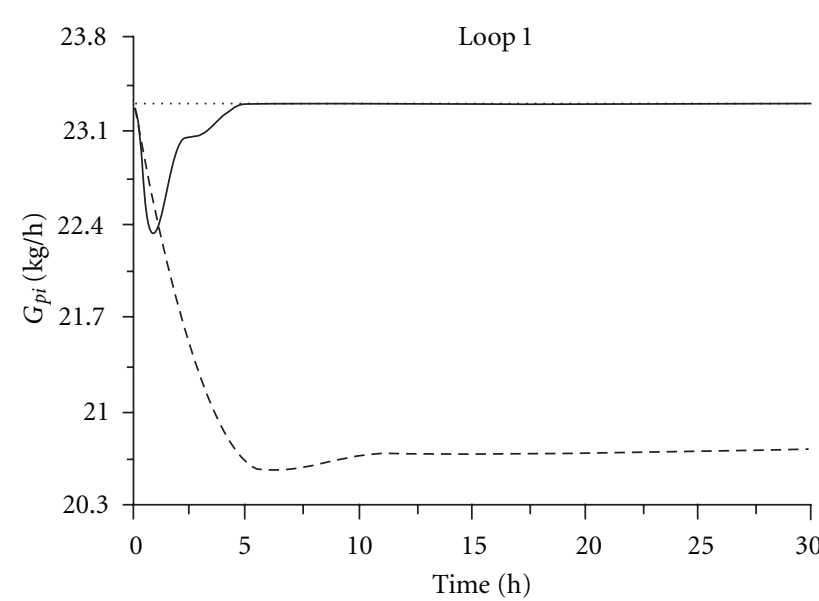

(a)

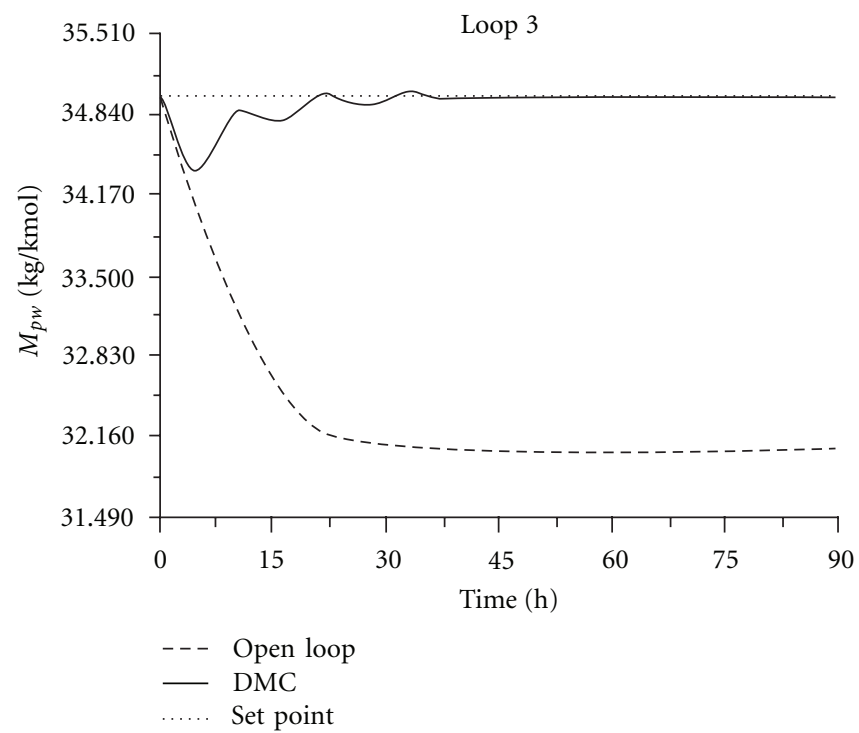

(c)

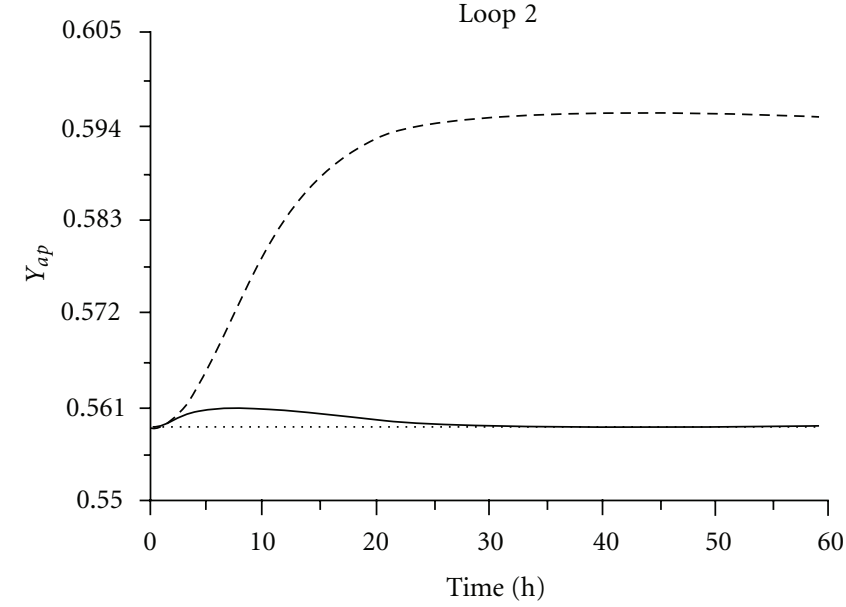

(b)

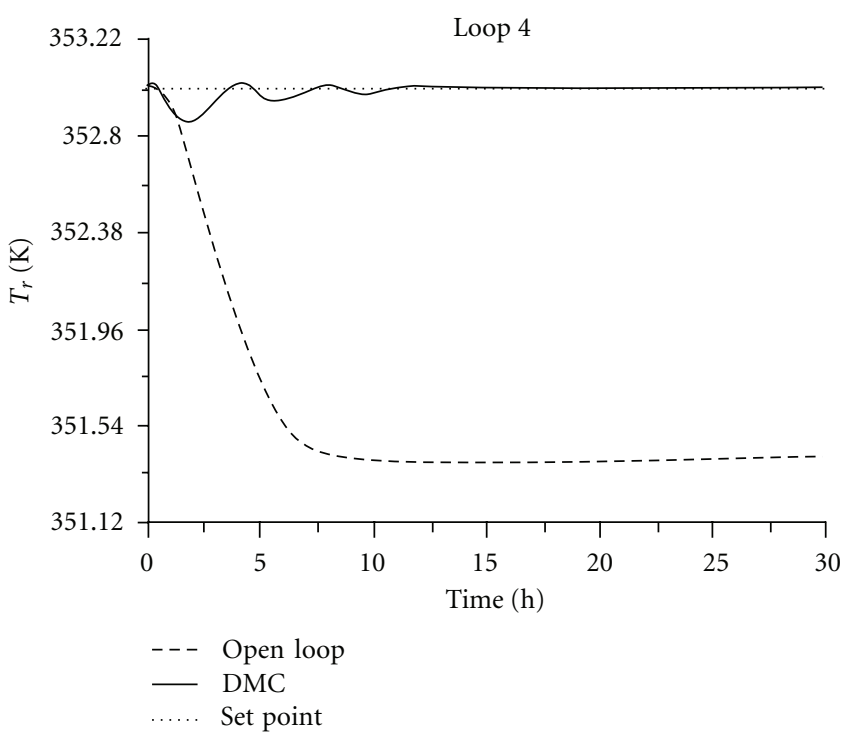

(d)

FIGURE 5: Closed-loop and open-loop simulations for an inhibitor disturbance of 4 parts per 1000 (mole basis).

Reactor, separator, and hold tank contain pure solvent preheated to $353.15 \mathrm{~K}$ at startup.

The steady-state operating point is reported in Table 1. Under these conditions, the reactor residence time is $\theta_{r}=$ $6 \mathrm{~h}$, and the overall reactor monomer conversion is $20 \%$. These operating conditions ensure that the viscosity of the reaction medium remains moderate. Table 1 also indicates that the temperature of the reactor feed $T_{r f}$ is practically equal to the reactor temperature $T_{r}$, because in this work, we have chosen to simulate reactor operation with a preheated feed, where the source of heat removal is through the jacket.

\section{Feedforward Control of Recycle}

The presence of the recycle stream introduces disturbances in the reactor feed which affect the polymer properties. Congalidis et al. [1] implemented a feedforward controller in the process to compensate for these disturbances by manip- ulating the fresh feeds to maintain a constant feed composition and flow to the reactor. Feedforward control of the recycle stream enabled the designer to separate the control of the reactor from the rest of the process. Thus, the feedforward control is also applied in this work and the reactor can be analyzed separately.

The feedforward control equations were obtained by writing component balances around the recycle addition point $[1,9,30]$. For example, the mole balance for monomer A is:

$$
F_{a 3}=F_{a 1}+y_{a 2} F_{2}
$$

Equation (5) is then solved for the fresh feed of monomer A since it is desired to keep to goal flow of monomer A to the reactor $\left(F_{a 3}\right)$ constant:

$$
F_{a 1}=F_{a 3}-y_{a 2} F_{2}
$$




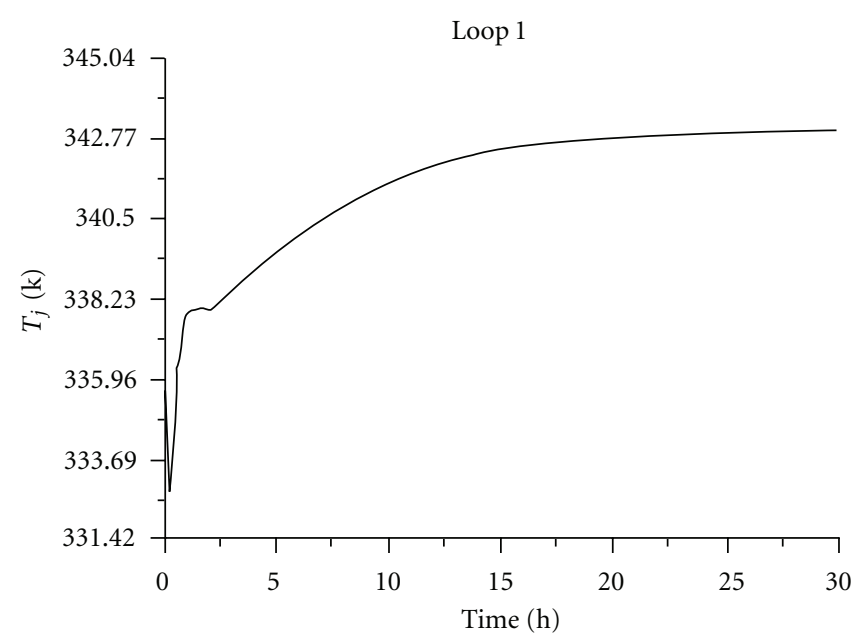

(a)

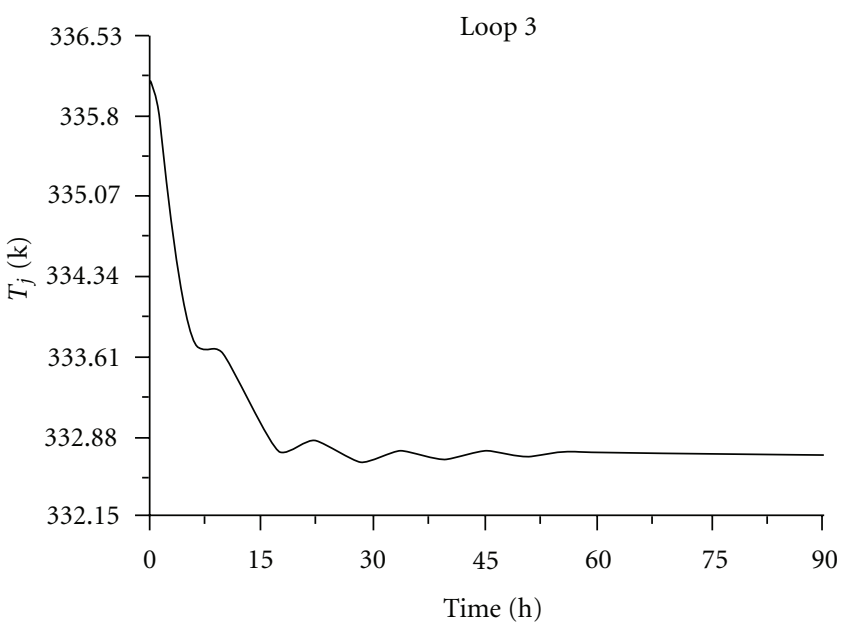

(c)

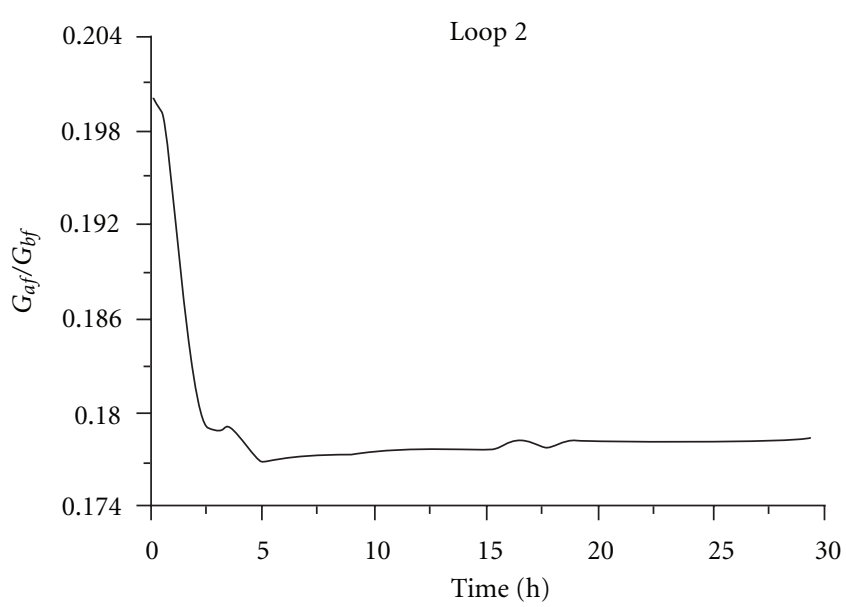

(b)

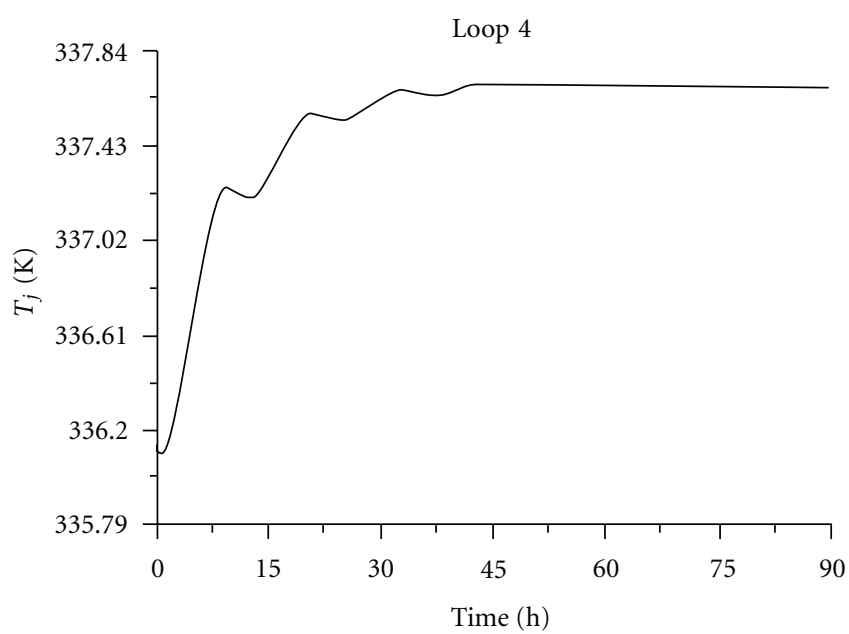

(d)

FIGURE 6: Manipulated variables profile for an inhibitor disturbance of 4 parts per 1000 (mole basis).

Since only monomers A and B and solvent are present in the recycle, only these three components have feedforward control equations. The corresponding equations for fresh feeds of monomer $B$ and solvent are:

$$
\begin{gathered}
F_{b 1}=F_{b 3}-y_{b 2} F_{2}, \\
F_{s 1}=F_{s 3}-y_{s 2} F_{2} .
\end{gathered}
$$

If any feedforward control equation causes a fresh feed to go negative, the value of that fresh feed is set to zero.

\section{Deterministic Model}

This case study is described by a nonlinear deterministic mathematical model. This model consists of a set of algebraic and ordinary differential equations which formally replace the real plant for the controller implementation. The deterministic model, as well as the kinetic mechanism and initial concentrations, is explained in detail in Appendix. More information on the nonlinear model is given in Congalidis et al. [1] and Maner and Doyle [30].

\section{Open-Loop Behavior and Selection of the Control Loops}

This system consists of six inputs $\left(G_{a f}, G_{b f}, G_{i f}, G_{t f}, G_{s f}\right.$, and $T_{j}$ ) and four outputs. The temperature of the reactor feed $\left(T_{r f}\right)$ is assumed to be constant and the purge ratio $(\xi)$ is regulated by the feedforward controller. As pointed out in Table 1, the inhibitor feed rate is normally no flow. With these considerations, the algebraic equations in the deterministic model were solved and the ordinary differential equations were numerically integrated by means of RungeKutta algorithm type implemented in Fortran 90 language.

The following four output variables of the process are analyzed separately: copolymer production rate $\left(G_{p i}\right)$, mole fraction of A in copolymer $\left(Y_{a p}\right)$, weight average molecular weight $\left(M_{p w}\right)$, and reactor temperature $\left(T_{r}\right)$.

The dynamic behavior of these four output variables is reported in Figure 2, where the system undergoes an inhibitor disturbance of 4 parts per 1000 (mole basis) in the fresh feed. This disturbance is the same as that considered 


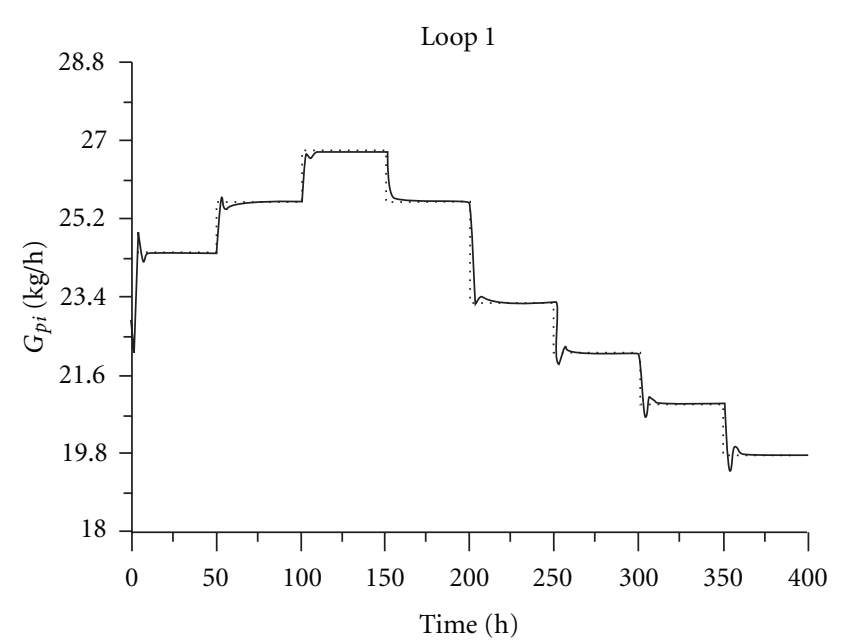

(a)

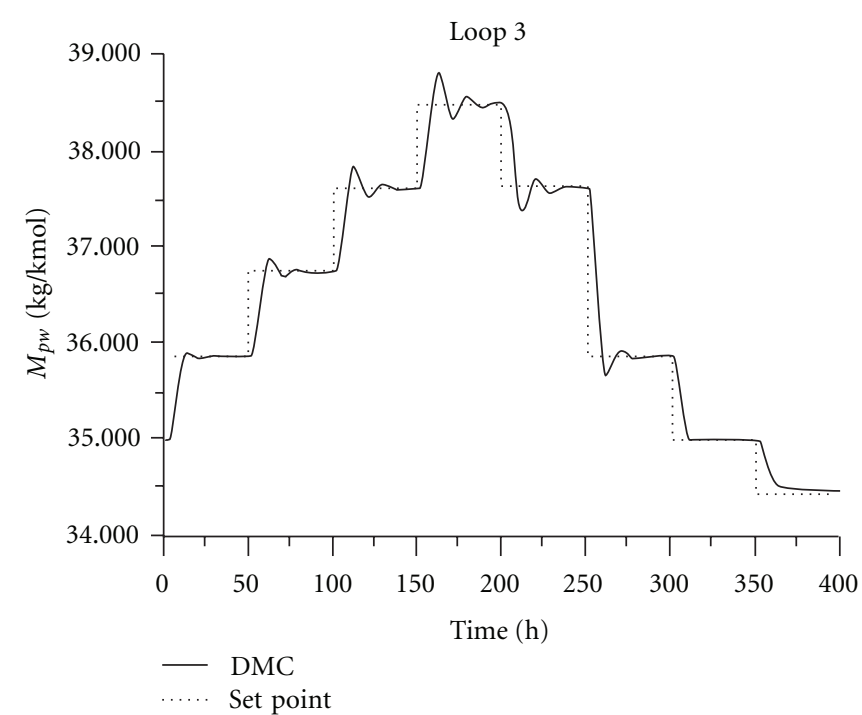

(c)

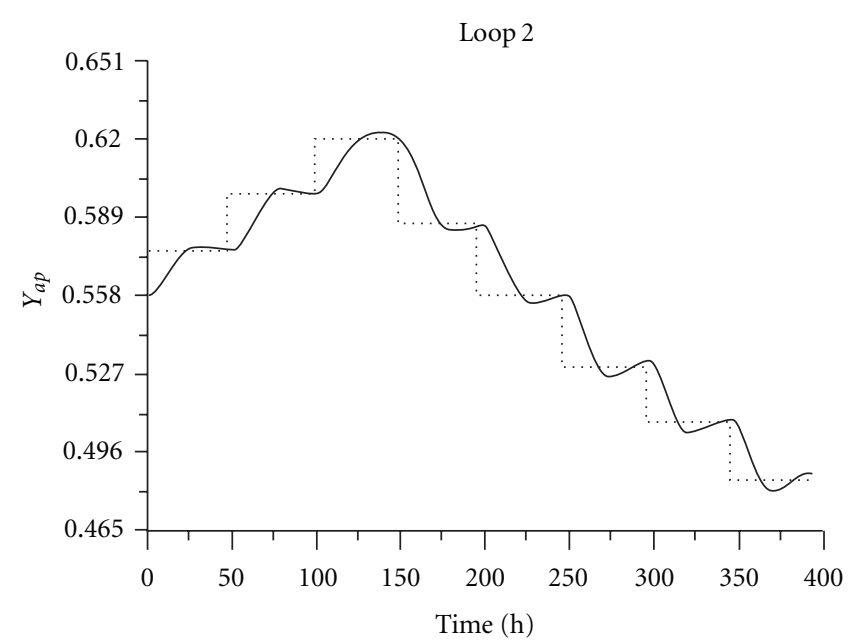

(b)

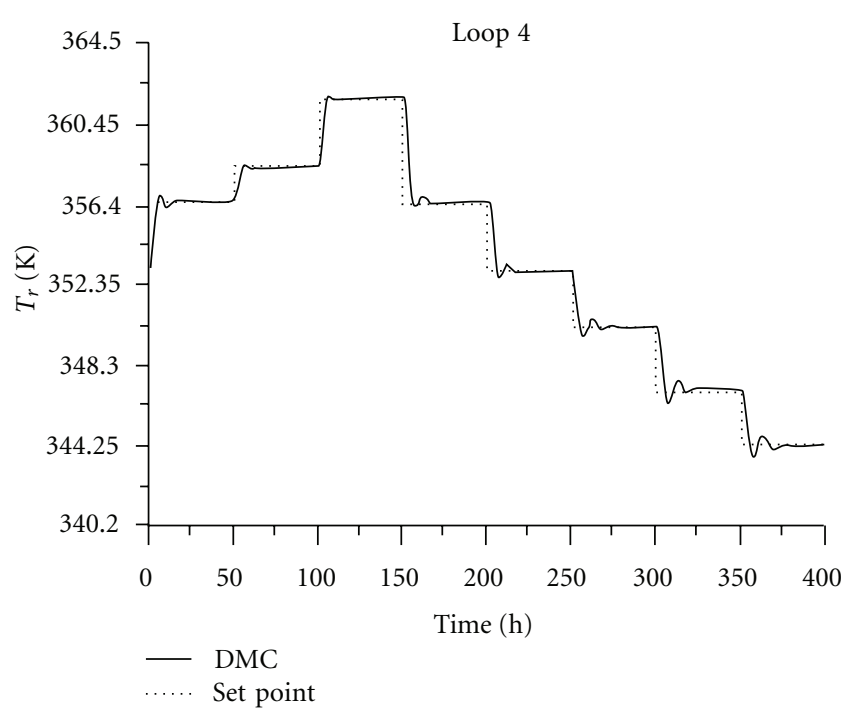

(d)

FIGURE 7: Closed-loop simulations for changes in set point.

by Maner and Doyle [30]. The fresh feed corresponds to the addition of the molar outflows of monomers, initiator, solvent, and chain transfer agent in the system entrance.

Figure 3 presents the dynamic trend of the weight average molecular weight $\left(M_{p w}\right)$ for symmetric step disturbances of in the reactor jacket temperature $\left(T_{j}\right)$, by highlighting process nonlinearities.

Lima et al. [31] developed a factorial planning using Statistica Version 7.0 Software to discriminate the higher impact variables on the process performance. According to this sensitivity analysis, the four selected SISO control loops are shown in Table 2. Figure 4 presents the location of each monovariable DMC loop and the feedforward controller. For the DMC control, the controlled variables are displayed in blue color, and the manipulated variables are displayed in red color.

\section{Performance of the Dynamic Matrix Control}

An algorithm for the proposed predictive controller was developed in Fortran 90 and further inserted in the simulaion program. Both regulatory and servo mechanism problems are taken into account to check DMC performances. Each SISO control loop was tuned separately.

7.1. Regulatory Problem. In this problem, an inhibitor disturbance of 4 parts per 1000 (mole basis) in the fresh feed was considered. Table 3 shows the parameters used for DMC in each control loop together with the control errors for this specific configuration. A comparison between DMC and open-loop responses is given in Figure 5; the corresponding manipulated variables for the closed-loop simulation are shown in Figure 6. The computational effort is in the order of $3 \mathrm{~s}$ for each control loop run. 


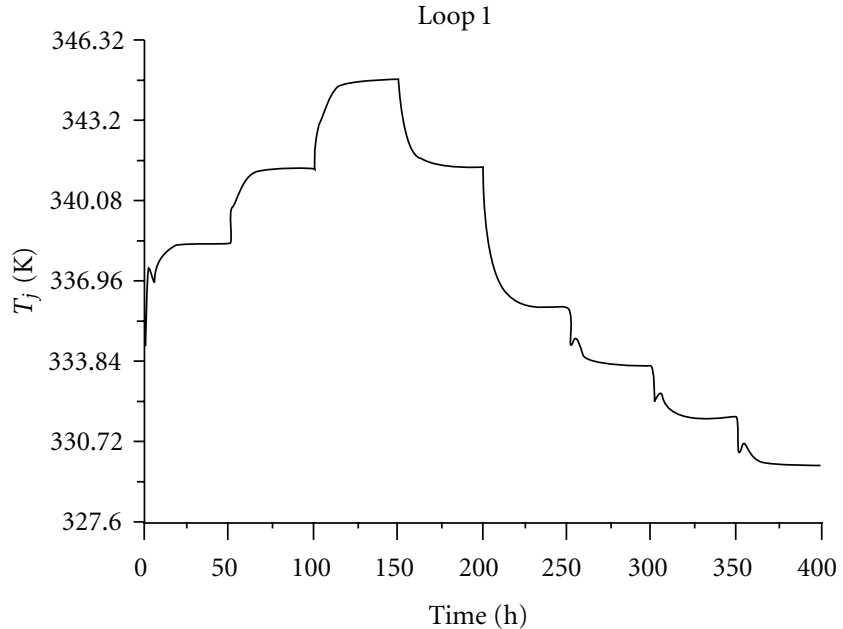

(a)

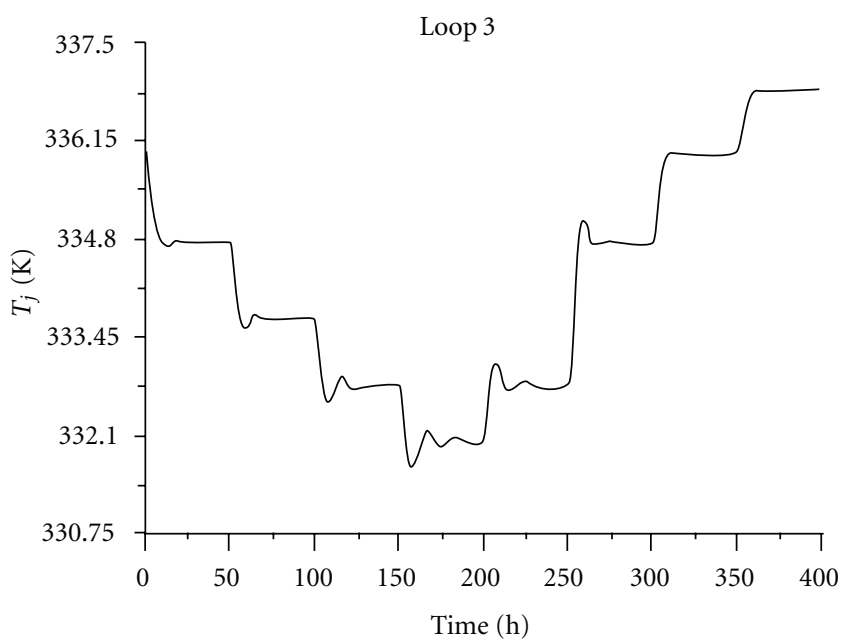

(c)

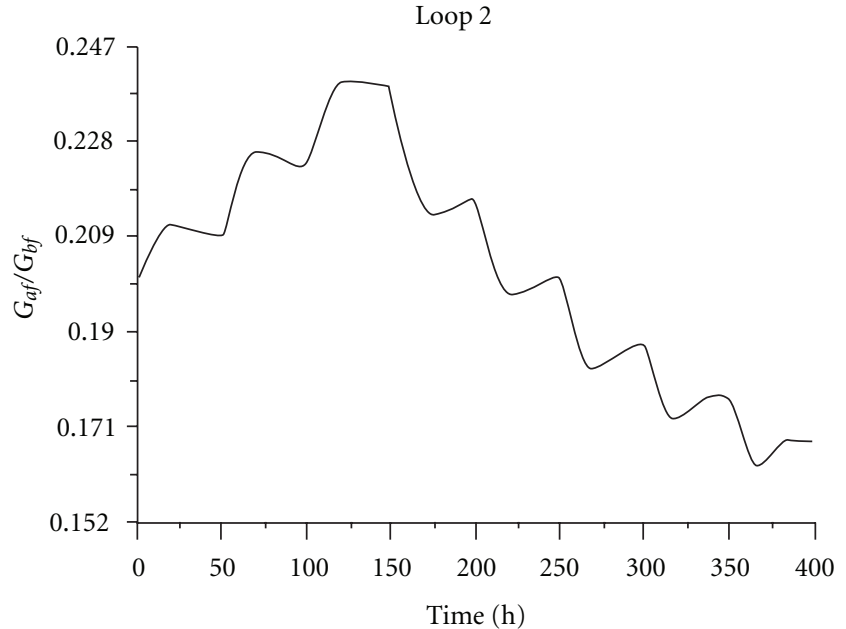

(b)

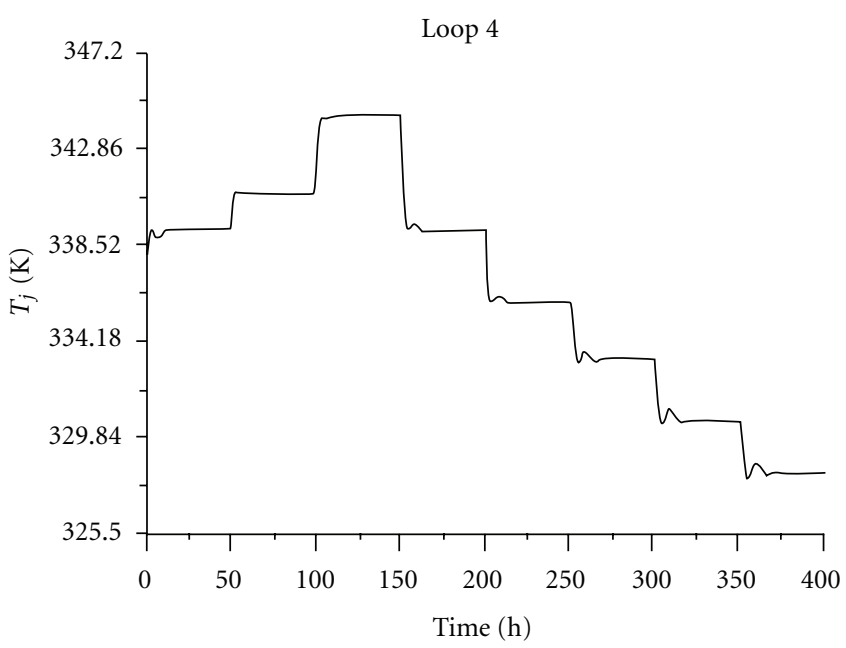

(d)

FIGURE 8: Manipulated variables profile for changes in set point.

As can be observed in Table 3 and Figure 5 the DMC structure performs satisfactorily, without abrupt changes and with small overshoots. Furthermore, Figure 6 shows that the manipulated variable behavior is quite acceptable presenting small oscillations, which is important for a stable operation.

7.2. Servo Problem. According to the regulatory problem, the parameters used for the DMC in each control loop and the control errors are given in Table 4. Figure 7 shows closed-loop performances of output variables, while the system undergoes a series of set point changes. The corresponding manipulated variables are given by Figure 8 . The computational effort is in the order of $2 \mathrm{~s}$ for each control loop run.

Table 4 and Figure 7 show that the performance of the DMC is fairly good with the polymer properties, since it is able to approach quickly the new set point. However, the $M_{p w}$ shows a more complex dynamic response, which is characteristic of the highly interactive dynamics of solution polymerization reactors. Moreover, Figure 8 shows that the manipulated variable behavior is quite acceptable without drastic changes in reaching the control objective illustrated in Figure 7.

\section{Effect of Control Parameters on Controller Performances}

Prediction horizon (PH) and suppression factor $(f)$ are the control parameters of greatest impact on the four output variables of the process, thus a sensitivity analysis of the control structures has been carried out for them. 


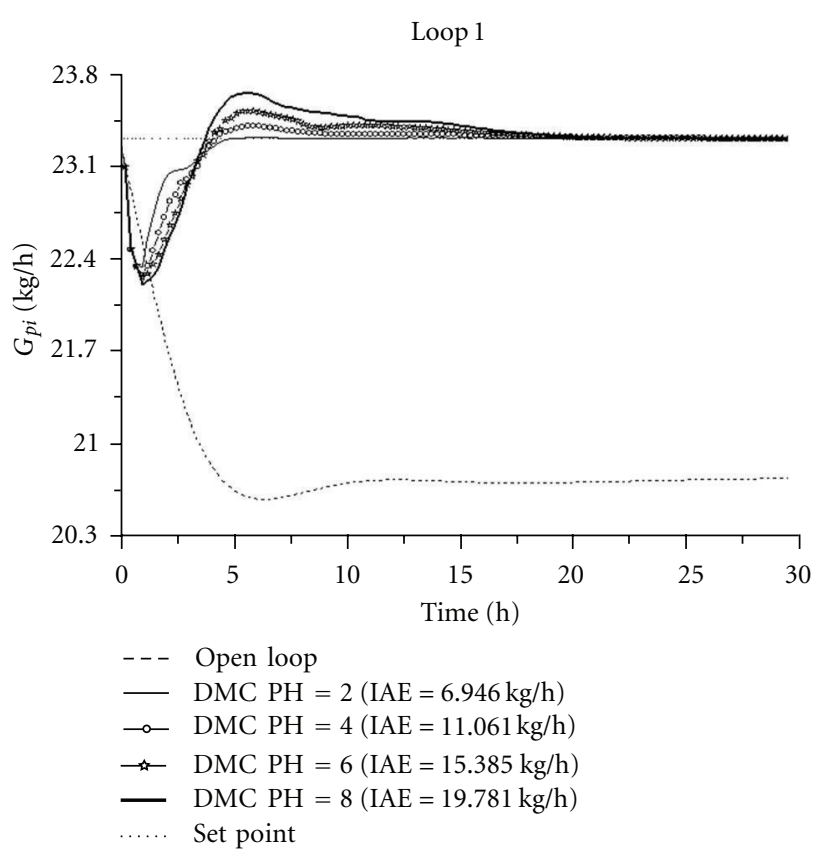

(a)

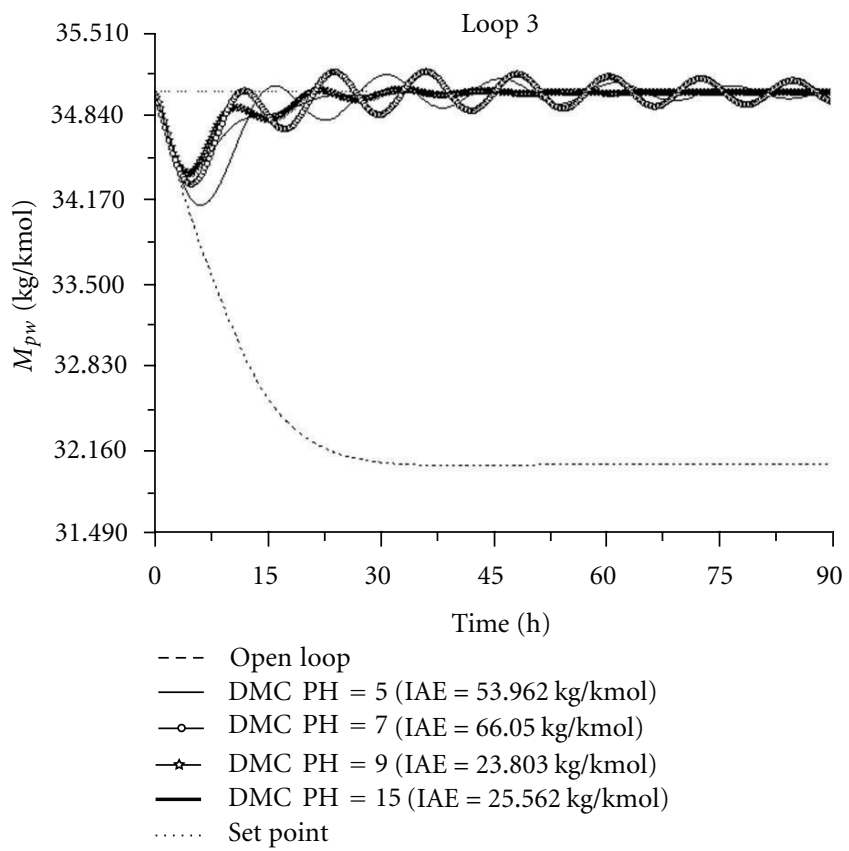

(c)

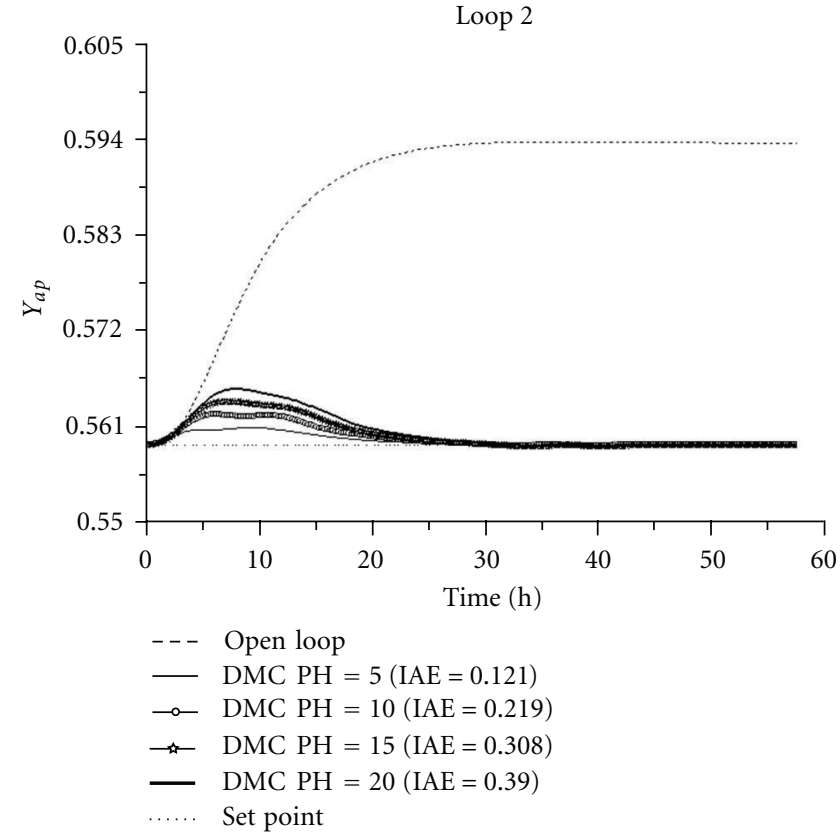

(b)

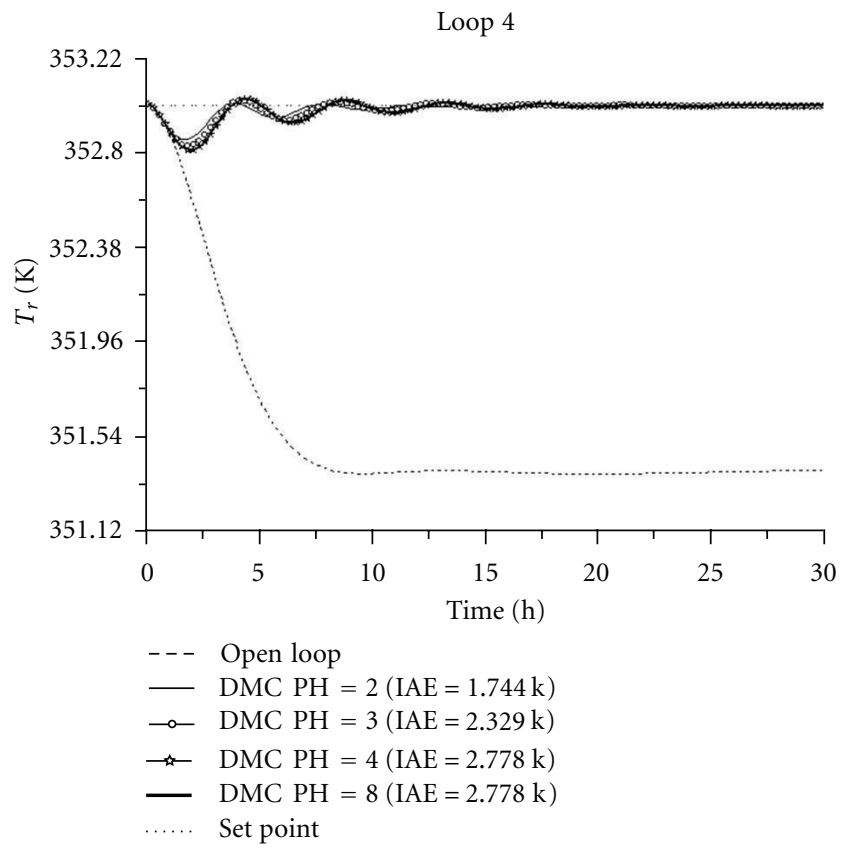

(d)

FIGURE 9: PH sensitivity simulations for an inhibitor disturbance of 4 parts per 1000 (mole basis).

Dealing with the regulatory problem for an inhibitor disturbance of 4 parts per 1000 (mole basis) in the fresh feed, Figure 9 and Figure 10 both show the closed-loop performance of the four controlled variables for changes in $\mathrm{PH}$ and in $f$, respectively. The values of the other control parameters are listed in Table 5. Figures 9 and 10 point out that the increase in $\mathrm{PH}$ or in $f$ takes to a larger control error; however, random values of the IAE are observed for changes in the $\mathrm{PH}$ for the loop number 3. It is also shown that the increase in $f$ provides a larger damping of the system, as somehow expected. This can be explained from the analysis of the control objective function $J(1)$.

For example, by analyzing the servo problem for the weight average molecular weight, Figure 11 shows the closedloop performance of this output variable for changes in $\mathrm{PH}$ and in $f$. The values of the other control parameters are presented in Table 6. Figure 11 shows that the increase in $\mathrm{PH}$ provides a smaller control error, whereas the opposite effect occurs for changes in $f$. Moreover, the increase in $f$ provides a larger damping of the system. 

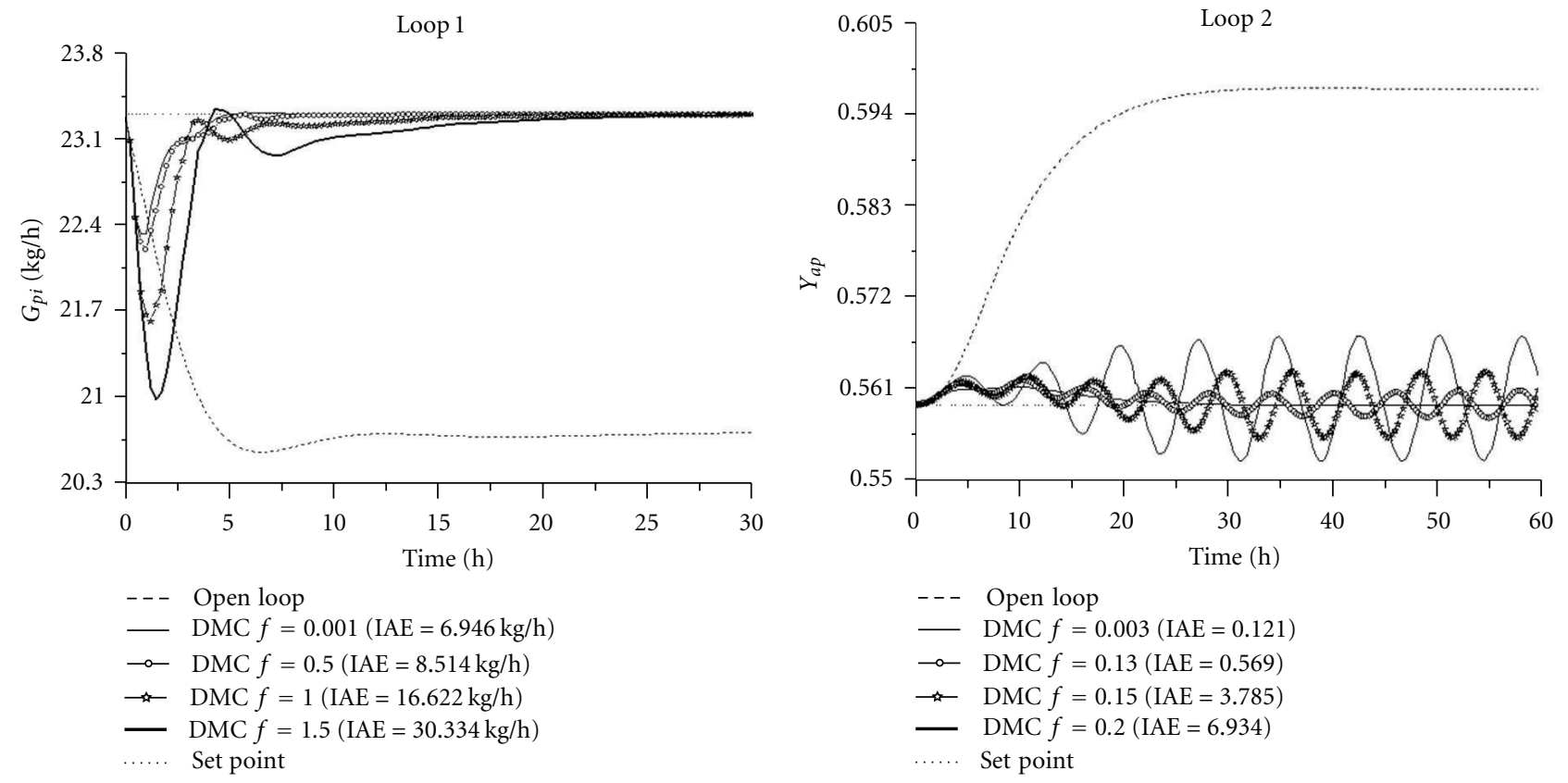

(a)

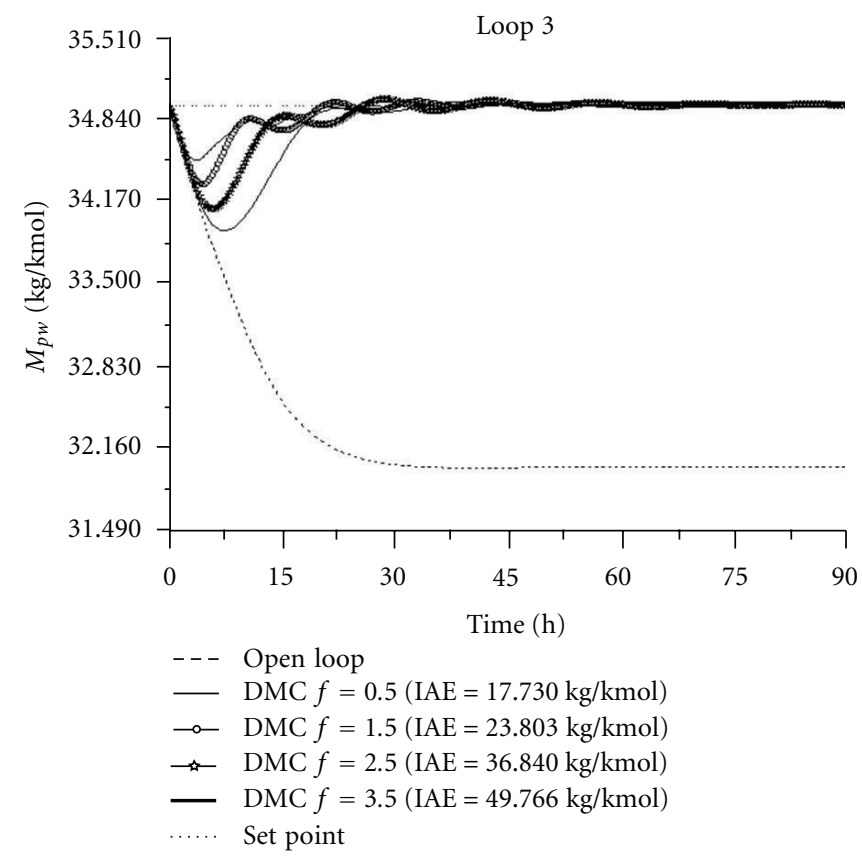

(c)

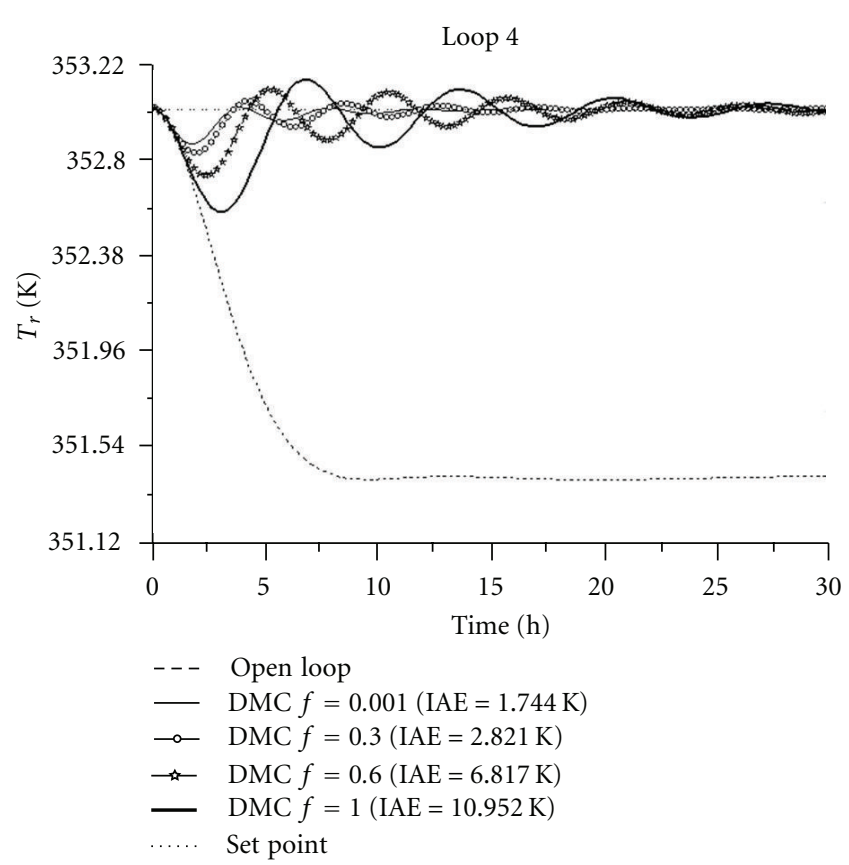

(d)

FIGURE 10: $f$ sensitivity simulations for an inhibitor disturbance of 4 parts per 1000 (mole basis).

\section{Conclusions}

The servo and regulatory performance of DMC, applied to a solution copolymerization jacketed reactor, has been analyzed. The simulation case-study was based on a nonlinear mathematical model that describes the liquid-full reactor. Closed-loop computer simulation results showed the successful behavior and the potential of the DMC methodology to reduce off-specifications during changes in copolymer production rate, mole fraction of monomer $\mathrm{A}$ in the copolymer, weight average molecular weight, and reactor temperature. From this perspective, performances of DMC methodology give the opportunity to move towards the socalled demand-driven production and, hence, to increase net operating margins of polymer plants by forcing the production to fast follow, when possible, the more and more frequent market dynamics and price/cost volatilities.

The DMC strategy showed robustness, having stable behavior for the four control loops even when large changes due to the optimization convergence are imposed on the 


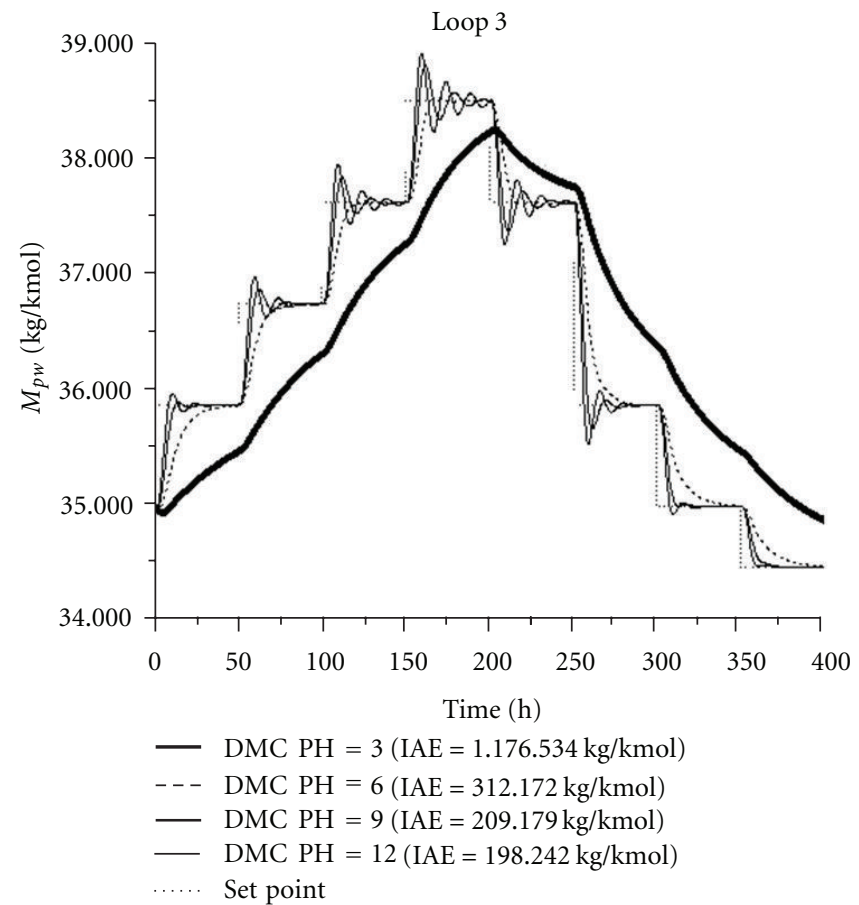

(a)

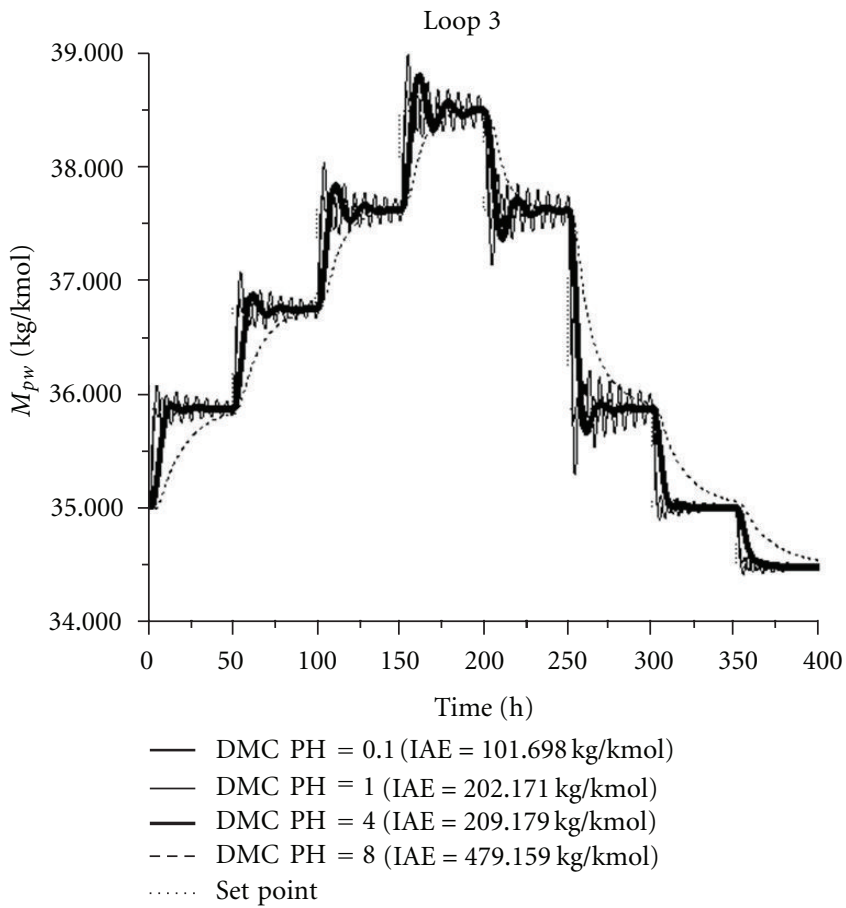

(b)

FIGURE 11: Closed-loop simulations for the servo problem for sensitivity analysis on $\mathrm{PH}$ and $f$.

TABLE 7: Kinetic mechanism for deterministic model.

(a)

\begin{tabular}{lr}
\hline Initiation & Propagation \\
\hline$I \stackrel{k_{i}}{\rightarrow} 2 I \bullet$ & $A_{n, m} \bullet+A \stackrel{k_{p a a}}{\longrightarrow} A_{n+1, m} \bullet$ \\
$I \bullet+A \stackrel{k_{i a}}{\longrightarrow} A_{1,0} \bullet$ & $A_{n, m} \bullet+B \stackrel{k_{p a b}}{\longrightarrow} B_{n, m+1} \bullet$ \\
$I \bullet+B \stackrel{k_{i b}}{\longrightarrow} B_{0,1} \bullet$ & $B_{n, m} \bullet+A \stackrel{k_{p b a}}{\longrightarrow} A_{n+1, m} \bullet$ \\
$S \bullet+A \stackrel{k_{i s}}{\longrightarrow} A_{1,0} \bullet$ & $B_{n, m} \bullet+B \stackrel{k_{p b b}}{\longrightarrow} B_{n, m+1} \bullet$ \\
$S \bullet+B \stackrel{k_{i s}}{\longrightarrow} B_{0,1} \bullet$ & \\
$T \bullet+A \stackrel{k_{i t}}{\longrightarrow} A_{1,0} \bullet$ & \\
$T \bullet+B \stackrel{k_{i t}}{\longrightarrow} B_{0,1} \bullet$ & \\
\hline
\end{tabular}

(b)

\begin{tabular}{lcc}
\hline Termination by coupling & Termination by disproportionation & Inhibition \\
\hline$A_{n, m} \bullet+A_{r, q} \bullet \stackrel{k_{c a a}}{\longrightarrow} P_{n+r, m+q}$ & $A_{n, m} \bullet+A_{r, q} \bullet \stackrel{k_{d a a}}{\longrightarrow} P_{n, m}+P_{r, q}$ & $A_{n, m} \bullet+Z \stackrel{k_{z a}}{\longrightarrow} P_{n, m}$ \\
$A_{n, m} \bullet+B_{r, q} \bullet \stackrel{k_{c a b}}{\longrightarrow} P_{n+r, m+q}$ & $A_{n, m} \bullet+B_{r, q} \bullet \stackrel{k_{d a b}}{\longrightarrow} P_{n, m}+P_{r, q}$ & $B_{n, m} \bullet+Z \stackrel{k_{z b}}{\longrightarrow} P_{n, m}$ \\
$B_{n, m} \bullet+B_{r, q} \bullet \stackrel{k_{c b b}}{\longrightarrow} P_{n+r, m+q}$ & $B_{n, m} \bullet+B_{r, q} \bullet \stackrel{k_{d b b}}{\longrightarrow} P_{n, m}+P_{r, q}$ & \\
\hline Chain transfer to monomer & Chain transfer to solvent & Chain transfer to agent \\
\hline$A_{n, m} \bullet+A \stackrel{k_{x a a}}{\longrightarrow} P_{n, m}+A_{1,0} \bullet$ & $A_{n, m} \bullet+S \stackrel{k_{x a s}}{\longrightarrow} P_{n, m}+S \bullet$ & $A_{n, m} \bullet+T \stackrel{k_{x a t}}{\longrightarrow} P_{n, m}+T \bullet$ \\
$A_{n, m} \bullet+B \stackrel{k_{x a b}}{\longrightarrow} P_{n, m}+B_{0,1} \bullet$ & $B_{n, m} \bullet+S \stackrel{k_{x b s}}{\longrightarrow} P_{n, m}+S \bullet$ & $B_{n, m} \bullet+T \stackrel{k_{x b t}}{\longrightarrow} P_{n, m}+T \bullet$ \\
$B_{n, m} \bullet+A \stackrel{k_{x b a}}{\longrightarrow} P_{n, m}+A_{1,0} \bullet$ & & \\
$B_{n, m} \bullet+B \stackrel{k_{x b b}}{\longrightarrow} P_{n, m}+B_{0,1} \bullet$ & & \\
\hline
\end{tabular}


TABLE 8: Kinetic and thermodynamic parameters for deterministic model.

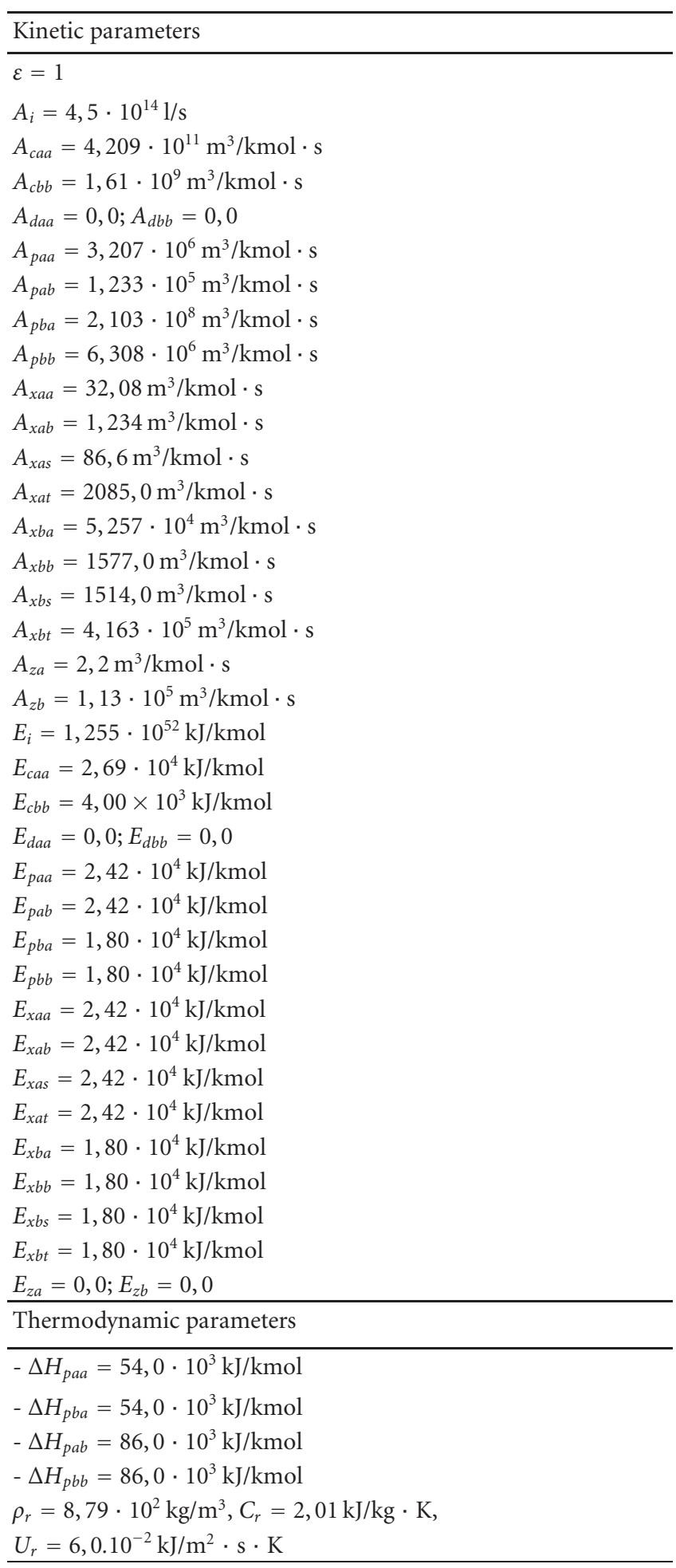

system. Another important breakthrough of the analyzed control strategy is its capacity to deal with nonstationary and nonlinear features, which are typical of polymerization systems. This means that the whole procedure proposed in this work has significant potential for application in several industrial processes similar to the type considered here.

\section{Appendix}

\section{A. Nonlinear Mathematical Model for the Copolymerization Reactor}

A.1. Kinetic Mechanism. The free radical kinetic mechanism shown in Table 7 is postulated for the polymerization of monomers A and B in the presence of initiator $(I)$, solvent $(S)$, chain transfer agent $(T)$, and inhibitor $(Z)[1]$. In this mechanism, $A_{n, m} \bullet$ and $B_{n, m} \bullet$ symbolize growing polymer chains containing $n$ units of monomer $\mathrm{A}$ and $m$ units of monomer $\mathrm{B}$ that terminate in $\mathrm{A}$ and $\mathrm{B}$, respectively. $P_{n, m}$ represents a "dead" polymer chain containing $n$ units of monomer $\mathrm{A}$ and $m$ units of monomer $\mathrm{B}$. In the calculation of the cross-termination rate constants, it has been assumed that $k_{c a b}=\sqrt{k_{c a a} \cdot k_{c b b}}$ and $k_{d a b}=\sqrt{k_{d a a} \cdot k_{d b b}}$.

Each of the kinetic rate constants shown in Table 7 is computed by an Arrhenius form such as:

$$
k=A \cdot e^{\left(-E / R \cdot T_{r}\right)} .
$$

Values for the Arrhenius factor $A$ and the activation energy $E$ are given in Table 8 [30].

A.2. Material and Energy Balances. Assuming that the reaction occurs in a CSTR with no volume change in the reacting mixture, the following mole balances can be written for the monomers, the initiator, the solvent, the chain transfer agent, and the inhibitor:

$$
\begin{gathered}
\frac{d C_{k}}{d t}=\frac{C_{k f}-C_{k}}{\theta_{r}}-R_{k}, \\
C_{k}(0)=C_{k 0}, \quad k=a, b, i, s, t, z, \\
R_{a}=\left[\left(k_{p a a}+k_{x a a}\right) \cdot C_{a}+\left(k_{p b a}+k_{x b a}\right) \cdot C_{b \bullet}\right] \cdot C_{a}, \\
R_{b}=\left[\left(k_{p b b}+k_{x b b}\right) \cdot C_{b \bullet}+\left(k_{p a b}+k_{x a b}\right) \cdot C_{a}\right] \cdot C_{b}, \\
R_{i}=k_{i} \cdot C_{i}, \\
R_{s}=\left(k_{x a s} \cdot C_{a \bullet}+k_{x b s} \cdot C_{b \bullet}\right) \cdot C_{s}, \\
R_{t}=\left(k_{x a t} \cdot C_{a \bullet}+k_{x b t} \cdot C_{b \bullet}\right) \cdot C_{t}, \\
R_{z}=\left(k_{z a} \cdot C_{a \bullet}+k_{z b} \cdot C_{b \bullet}\right) \cdot C_{z} .
\end{gathered}
$$

The reactor feed volumetric flow rate, concentrations, and reactor residence time are calculated by:

$$
\begin{gathered}
Q_{f}=\sum_{k} \frac{F_{k f} \cdot M_{k}}{\rho_{r}}, \\
C_{k f}=\frac{F_{k f}}{Q_{f}}, \\
\theta_{r}=\frac{V_{r}}{Q_{f}} .
\end{gathered}
$$


Using the quasi steady-state assumption, the following expressions can be derived for the total reactor concentrations of the free radicals terminating in A or B:

$$
\begin{aligned}
& C_{a} \cdot=\frac{-l_{2}+\sqrt{l_{2}^{2}-4 \cdot l_{1} \cdot l_{3}}}{2 \cdot l_{1}}, \\
& C_{b} \cdot=\beta \cdot C_{a}, \\
& \beta=\frac{\left(k_{p a b}+k_{x a b}\right) \cdot C_{b}}{\left(k_{p b a}+k_{x b a}\right) \cdot C_{a}}, \\
& l_{1}=k_{c a a}+k_{d a a}+2 \cdot \beta \cdot\left(k_{c a b}+k_{d a b}\right)+\beta^{2} \cdot\left(k_{c b b}+k_{d b b}\right) \text {, } \\
& l_{2}=C_{z} \cdot\left(k_{z a}+\beta \cdot k_{z b}\right) \text {, } \\
& l_{3}=-2 \cdot k_{i} \cdot C_{i} \cdot \varepsilon \text {. }
\end{aligned}
$$

These equations are coupled with the following reactor energy balance:

$$
\begin{aligned}
\frac{d T_{r}}{d t} & \\
= & \frac{T_{r f}-T_{r}}{\theta_{r}} \\
& +\frac{\left(-\Delta H_{p a a}\right) \cdot k_{p a a} \cdot C_{a} \cdot C_{a}+\left(-\Delta H_{p b a}\right) \cdot k_{p b a} C_{a} \cdot C_{b}}{\rho_{r} \cdot c_{r}} \\
& +\frac{\left(-\Delta H_{p a b}\right) \cdot k_{p a b} \cdot C_{b} \cdot C_{a}+\left(-\Delta H_{p b b}\right) \cdot k_{p b b} \cdot C_{b} \cdot C_{b} \bullet}{\rho_{r} \cdot c_{r}} \\
& -\frac{U_{r} \cdot S_{r}\left(T_{r}-T_{j}\right)}{V_{r} \cdot \rho_{r} \cdot c_{r}}, \\
T_{r}(0) \quad & T_{r 0} .
\end{aligned}
$$

The instantaneous polymerization rate is:

$$
G_{p i}=\left(R_{a} \cdot M_{a}+R_{b} \cdot M_{b}\right) \cdot V_{r}
$$

A.3. Dead Copolymer Composition. The following mole balances can be written for the calculation of the molar concentrations of the monomers in the dead polymer:

$$
\begin{array}{ll}
\frac{d \lambda_{a}}{d t}=\frac{\lambda_{a f}-\lambda_{a}}{\theta_{r}}+R_{a}, & \lambda_{a}(0)=\lambda_{a 0}, \\
\frac{d \lambda_{b}}{d t}=\frac{\lambda_{b f}-\lambda_{b}}{\theta_{r}}+R_{b}, & \lambda_{b}(0)=\lambda_{b 0} .
\end{array}
$$

The molar fraction of monomer A in dead polymer is calculated as follows:

$$
y_{a p}=\frac{\lambda_{a}}{\lambda_{a}+\lambda_{b}} .
$$

A.4. Moments of the Molecular Weight Distribution of the Dead Copolymer. Assuming that the reaction occurs in a CSTR, the following expressions can be derived:

$$
\begin{aligned}
& \frac{d \psi_{0}^{p}}{d t}=\frac{\psi_{0 f}^{p}-\psi_{0}^{p}}{\theta_{r}}+\frac{1}{2} \cdot k_{c a a} \cdot\left(\psi_{0}^{a \bullet}\right)^{2}+k_{c a b} \cdot \psi_{0}^{a \bullet} \cdot \psi_{0}^{b \bullet} \\
& +\frac{1}{2} \cdot k_{c b b} \cdot\left(\psi_{0}^{b \bullet}\right)^{2}+L_{1} \cdot \psi_{0}^{a \bullet}+L_{2} \cdot \psi_{0}^{b \bullet}, \\
& \psi_{0}^{p}(0)=\psi_{0 o}^{p} \text {, } \\
& \frac{d \psi_{1}^{p}}{d t}=\frac{\psi_{1 f}^{p}-\psi_{1}^{p}}{\theta_{r}}+k_{c a a} \cdot \psi_{0}^{a \bullet} \cdot \psi_{1}^{a \bullet} \\
& +k_{c a b} \cdot\left(\psi_{0}^{a \bullet} \cdot \psi_{1}^{b \bullet}+\psi_{0}^{b \bullet} \cdot \psi_{1}^{a \bullet}\right) \\
& +k_{c b b} \cdot \psi_{0}^{b \bullet} \cdot \psi_{1}^{b \bullet}+L_{1} \cdot \psi_{1}^{a \bullet}+L_{2} \cdot \psi_{1}^{b \bullet}, \\
& \psi_{1}^{p}(0)=\psi_{1 o}^{p} \text {, } \\
& \frac{d \psi_{2}^{p}}{d t}=\frac{\psi_{2 f}^{p}-\psi_{2}^{p}}{\theta_{r}}+k_{c a a} \cdot\left[\left(\psi_{1}^{a \bullet}\right)^{2}+\psi_{0}^{a \bullet} \cdot \psi_{2}^{a \bullet}\right] \\
& +k_{c a b} \cdot\left(2 \cdot \psi_{1}^{a \bullet} \cdot \psi_{1}^{b \bullet}+\psi_{2}^{b \bullet} \cdot \psi_{0}^{a \bullet}+\psi_{2}^{a \bullet} \cdot \psi_{0}^{b \bullet}\right) \\
& +k_{c b b} \cdot\left[\left(\psi_{1}^{b \bullet}\right)^{2}+\psi_{0}^{b \bullet} \cdot \psi_{2}^{b \bullet}\right] \\
& +L_{1} \cdot \psi_{2}^{a \bullet}+L_{2} \cdot \psi_{2}^{b \bullet}, \\
& \psi_{2}^{p}(0)=\psi_{2 o}^{p} \\
& L_{1}=k_{x a s} \cdot C_{s}+k_{x a a} \cdot C_{a}+k_{x a b} \cdot C_{b} \\
& +k_{x a t} \cdot C_{t}+k_{z a} \cdot C_{z}+k_{d a a} \cdot C_{a \bullet}+k_{d a b} \cdot C_{b \bullet}, \\
& L_{2}=k_{x b s} \cdot C_{s}+k_{x b b} \cdot C_{b}+k_{x b a} \cdot C_{a} \\
& +k_{x b t} \cdot C_{t}+k_{z b} \cdot C_{z}+k_{d b b} \cdot C_{b \bullet}+k_{d a b} \cdot C_{a \bullet} .
\end{aligned}
$$

The number and weight average molecular weights of the dead copolymer are then computed by the following relationships:

$$
\begin{gathered}
M_{p n}=\frac{\psi_{1}^{p}}{\psi_{0}^{p}}, \\
M_{p w}=\frac{\psi_{2}^{p}}{\psi_{1}^{p}} .
\end{gathered}
$$

A.5. Moments of the Molecular Weight Distribution of the Live Copolymer. These moments are the same for all reactors and depend only on the local reaction environment:

$$
\begin{aligned}
& \psi_{0}^{a \bullet}=\frac{B_{3}}{B_{1}}, \\
& \psi_{1}^{a \bullet}=\frac{\alpha_{1} \cdot \alpha_{2} \cdot V_{1} \cdot\left(M_{b}+M_{a}\right)+\alpha_{1} \cdot c_{1} \cdot M_{a}}{B_{1}}-\frac{B_{2} \cdot B_{3}}{B_{1}^{2}},
\end{aligned}
$$




$$
\begin{aligned}
& \psi_{2}^{a \bullet}=\frac{-B_{3} \cdot\left[\left(\alpha_{1}+\alpha_{2}\right) \cdot M_{a} \cdot M_{b}+B_{2} \cdot\left(M_{a}+M_{b}-1\right)\right]}{B_{1}^{2}} \\
& +\frac{\alpha_{1} \cdot \alpha_{2} \cdot V_{1} \cdot\left(M_{a}+M_{b}-1\right) \cdot\left(M_{a}+M_{b}\right)}{B_{1}} \\
& +\frac{\alpha_{1} \cdot c_{1} \cdot M_{a} \cdot\left(M_{a}-1\right)}{B_{1}}+\frac{2 \cdot B_{2}^{2} \cdot B_{3}}{B_{1}^{3}}+\psi_{1}^{a} \bullet \\
& -\frac{2 \cdot B_{2} \cdot\left[\alpha_{1} \cdot \alpha_{2} \cdot V_{1} \cdot\left(M_{a}+M_{b}\right)+\alpha_{1} \cdot c_{1} \cdot M_{a}\right]}{B_{1}^{2}}, \\
& \psi_{0}^{b \bullet}=\frac{B_{4}}{B_{1}} \\
& \psi_{1}^{b \bullet}=\frac{\alpha_{1} \cdot \alpha_{2} \cdot V_{2} \cdot\left(M_{b}+M_{a}\right)+\alpha_{2} \cdot c_{4} \cdot M_{b}}{B_{1}}-\frac{B_{2} \cdot B_{4}}{B_{1}^{2}}, \\
& \psi_{2}^{b \bullet}=\frac{-B_{4} \cdot\left[\left(\alpha_{1}+\alpha_{2}\right) \cdot M_{a} \cdot M_{b}+B_{2} \cdot\left(M_{a}+M_{b}-1\right)\right]}{B_{1}^{2}} \\
& +\frac{\alpha_{1} \cdot \alpha_{2} \cdot V_{2} \cdot\left(M_{a}+M_{b}-1\right) \cdot\left(M_{a}+M_{b}\right)}{B_{1}} \\
& +\frac{\alpha_{2} \cdot c_{4} \cdot M_{b} \cdot\left(M_{b}-1\right)}{B_{1}}+\frac{2 \cdot B_{2}^{2} \cdot B_{4}}{B_{1}^{3}}+\psi_{1}^{b} \\
& -\frac{2 \cdot B_{2} \cdot\left[\alpha_{1} \cdot \alpha_{2} \cdot V_{2} \cdot\left(M_{a}+M_{b}\right)+\alpha_{2} \cdot c_{4} \cdot M_{b}\right]}{B_{1}^{2}}, \\
& \alpha_{1}=\frac{k_{p a a} \cdot C_{a}}{\mathcal{A}} \\
& \alpha_{2}=\frac{k_{p b b} \cdot C_{b}}{\mathscr{B}} \text {, } \\
& c_{1}=\frac{2 \cdot k_{i} \cdot \varepsilon \cdot C_{i}+C_{s} \cdot\left(k_{x a s} \cdot C_{a \bullet}+k_{x b s} \cdot C_{b \bullet}\right)}{k_{p a a} \cdot\left(C_{a}+C_{b}\right)} \\
& +\frac{C_{t} \cdot\left(k_{x a t} \cdot C_{a \bullet}+k_{x b t} \cdot C_{b \bullet}\right)}{k_{p a a} \cdot\left(C_{a}+C_{b}\right)} \\
& +\frac{k_{x a a} \cdot C_{a} \cdot k_{x b a} \cdot C_{b \bullet}}{k_{p a a}}, \\
& c_{4}=\frac{2 \cdot k_{i} \cdot \varepsilon \cdot C_{i}+C_{s} \cdot\left(k_{x a s} \cdot C_{a \bullet}+k_{x b s} \cdot C_{b \bullet}\right)}{k_{p b b} \cdot\left(C_{a}+C_{b}\right)} \\
& +\frac{C_{t} \cdot\left(k_{x a t} \cdot C_{a \bullet}+k_{x b t} \cdot C_{b \bullet}\right)}{k_{p b b} \cdot\left(C_{a}+C_{b}\right)} \\
& +\frac{k_{x b b} \cdot C_{b \bullet}+k_{x a b} \cdot C_{a \bullet}}{k_{p b b}}, \\
& r_{1}=\frac{k_{p a a}}{k_{p a b}} \\
& r_{2}=\frac{k_{p b b}}{k_{p b a}}, \\
& \gamma=\frac{k_{p b a}}{k_{p a b}} \\
& c_{2}=c_{4} \cdot r_{2} \cdot \gamma \text {, }
\end{aligned}
$$$$
c_{3}=\frac{c_{1} \cdot r_{1}}{\gamma}
$$

$$
\begin{aligned}
x & =\frac{1}{r_{1} \cdot r_{2}}, \\
V_{1} & =c_{2} \cdot x-c_{1}, \\
V_{2} & =c_{3} \cdot x-c_{4}, \\
B_{1} & =1-\left(\alpha_{1}+\alpha_{2}\right)+\alpha_{1} \cdot \alpha_{2} \cdot(1-x), \\
B_{2} & =\left(M_{a}+M_{b}\right) \cdot(1-x) \cdot \alpha_{1} \cdot \alpha_{2}-\alpha_{1} \cdot M_{a}-\alpha_{2} \cdot M_{b}, \\
B_{3} & =\alpha_{1} \cdot c_{1}+\alpha_{1} \cdot \alpha_{2} \cdot V_{1}, \\
B_{4} & =\alpha_{2} \cdot c_{4}+\alpha_{1} \cdot \alpha_{2} \cdot V_{2},
\end{aligned}
$$

where $\mathcal{A}$ and $\mathcal{B}$ denotes $\left[\left(k_{c a a}+k_{d a a}\right) \cdot C_{a \bullet}+\left(k_{c a b}+k_{d a b}\right) \cdot C_{b \bullet}+\right.$ $\left.\left(k_{p a a}+k_{x a a}\right) \cdot C_{a}+\left(k_{p a b}+k_{x a b}\right) \cdot C_{b}+k_{x a t} \cdot C_{t}+k_{x a s} \cdot C_{s}+k_{z a} \cdot C_{z}\right]$ and $\left[\left(k_{c b b}+k_{d b b}\right) \cdot C_{b \bullet}+\left(k_{c a b}+k_{d a b}\right) \cdot C_{a \bullet}+\left(k_{p b b}+k_{x b b}\right) \cdot C_{b}+\right.$ $\left.\left(k_{p b a}+k_{x b a}\right) \cdot C_{a}+k_{x b t} \cdot C_{t}+k_{x b s} \cdot C_{s}+k_{z b} \cdot C_{z}\right]$, respectivly.

A.6. Separator and Hold Tank Balances. These pieces of equipment are modeled as first-order lags on the species concentrations with constant level:

$$
\begin{gathered}
\frac{d C_{k s}}{d t}=\frac{C_{k s f}-C_{k s}}{\theta_{s}} \quad C_{k s}(0)=C_{k s o}, \quad k=a, b, i, s, t, z, \\
\frac{d C_{k h}}{d t}=\frac{C_{k h f}-C_{k h}}{\theta_{h}} \quad C_{k h}(0)=C_{k h o}, \quad k=a, b, i, s, t, z .
\end{gathered}
$$

\section{Notation}

$\begin{array}{ll}\text { A: } & \text { Monomer A } \\ A: & \text { Arrhenius pre-exponential factor } \\ \mathrm{B}: & \text { Monomer B } \\ C: & \text { Concentration, } \mathrm{kmol} / \mathrm{m}^{3} \\ c: & \text { Heat capacity, } \mathrm{kJ} / \mathrm{kg} / \mathrm{K} \\ \mathrm{CH}: & \text { Control horizon } \\ \mathrm{CSTR}: & \text { Continuous stirred tank reactor } \\ \mathrm{DMC}: & \text { Dynamic matrix controller } \\ E: & \text { Activation energy, } \mathrm{kJ} / \mathrm{kmol} \\ F: & \text { Molar flow rate, } \mathrm{kmol} / \mathrm{s} \\ f: & \text { Suppression factor } \\ G: & \text { Mass flow rate, } \mathrm{kg} / \mathrm{h} \\ H: & \text { Enthalpy, } \mathrm{kJ} / \mathrm{kmol} \\ I: & \text { Initiator } \\ \mathrm{IAE}: & \text { Integral of the absolute value of the error } \\ k: & \text { Kinetic rate constant } \\ L: & \text { Intermediate variable in molecular weight } \\ & \text { distribution calculations } \\ M: & \text { Molecular weight, } \mathrm{kg} / \mathrm{kmol} \\ \mathrm{MPC}: & \text { Model predictive control } \\ P: & \text { Dead polymer } \\ \mathrm{PH}: & \text { Prediction horizon } \\ \mathrm{Q}: & \text { Volumetric flow rate, } \mathrm{m}^{3} / \mathrm{s} \\ R: & \text { Gas constant, } \mathrm{kJ} / \mathrm{kmol} / \mathrm{K} ; \text { reaction rate, } \\ & \text { kmol/m }{ }^{3} / \mathrm{s} ; \text { ratio }\end{array}$




\section{Superscripts}

$r$ : Reactivity ratio

S: Surface area, $\mathrm{m}^{2}$; solvent

$T$ : Temperature, K; chain transfer agent

$t$ : Time

$U$ : Overall heat transfer coefficient, $\mathrm{kJ} / \mathrm{m}^{2} / \mathrm{s} / \mathrm{K}$

$u$ : Input variable of the process

$V$ : Volume, $\mathrm{m}^{3}$

$y$ : Output variable of the process, mole fraction

$Y$ : Mole fraction

$x$ : Intermediate variable in molecular weight distribution calculations

$Z$ : Inhibitor.

\section{Greek letters}

$\alpha$ : Reference trajectory parameter, intermediate variable in molecular weight distribution calculations

$\beta$ : Intermediate variable in molecular weight distribution calculations

$\gamma$ : Intermediate variable in molecular weight distribution calculations

$\varepsilon$ : Initiator efficiency

$\theta$ : Residence time

$\lambda$ : Molar concentration of monomer in polymer macromolecules

$\xi:$ Molar purge fraction

$\rho$ : Density, $\mathrm{kg} / \mathrm{m}^{3}$

$\psi$ : Moment of molecular weight distribution

\section{Subscripts}

\section{a: Monomer A}

$b$ : Monomer B

c: Termination by coupling

CL: Closed-loop

$d$ : Termination by disproportionation

$f$ : Feed to the reactor, final time of the evaluation period

$h$ : Hold tank

$i$ : Initiator

$j$ : Cooling jacket

$k$ : Time instant

$m$ : Number of B units in polymer chain

$n$ : Number of A units in polymer chain

$o$ : Initial value

p: Dead polymer, propagation

$q$ : Number of B units in polymer chain

$r$ : Reactor, number of A units in polymer chain

$s$ : Solvent, steady-state value, separator

$t$ : Chain transfer agent

$w$ : Weight (average polymer property)

$z: \quad$ Inhibitor

0 : Initial time of the evaluation period

$(\bullet)$ : Free radical. actual: Actual value

$d$ : Desired output value

Future: Future value

Pred: Predicted value

Set: Set point

\section{Acknowledgments}

The authors acknowledge FAPESP (Fundação de Amparo à Pesquisa do Estado de São Paulo) and CNPq (Conselho Nacional de Desenvolvimento Científico e Tecnológico) for financial support.

\section{References}

[1] J. P. Congalidis, J. R. Richards, and W. H. Ray, "Feedforward and feedback control of a solution copolymerization reactor," AIChE Journal, vol. 35, no. 6, pp. 891-907, 1989.

[2] P. Mhaskar, "Robust model predictive control design for faulttolerant control of process systems," Industrial and Engineering Chemistry Research, vol. 45, no. 25, pp. 8565-8574, 2006.

[3] M. Mahmood and P. Mhaskar, "Enhanced stability regions for model predictive control of nonlinear process systems," AIChE Journal, vol. 54, no. 6, pp. 1487-1498, 2008.

[4] P. Mhaskar and A. B. Kennedy, "Robust model predictive control of nonlinear process systems: handling rate constraints," Chemical Engineering Science, vol. 63, no. 2, pp. 366-375, 2008.

[5] F. Manenti, I. Dones, G. Buzzi-Ferraris, and H. A. Preisig, "Efficient numerical solver for partially structured differential and algebraic equation systems," Industrial and Engineering Chemistry Research, vol. 48, no. 22, pp. 9979-9984, 2009.

[6] M. P. Vega, E. L. Lima, and J. C. Pinto, "Modeling and control of tubular solution polymerization reactors," Computers and Chemical Engineering, vol. 21, no. 1, pp. S1049-S1054, 1997.

[7] P. D. Schnelle and D. L. Rollins, "Industrial Model Predictive Control technology as applied to continuous polymerization processes," ISA Transactions, vol. 36, no. 4, pp. 281-292, 1997.

[8] N. M. N. Lima, F. Manenti, R. Maciel Filho, M. Embiruçu, and M. R. Wolf Maciel, "Fuzzy model-based predictive hybrid control of polymerization processes," Industrial and Engineering Chemistry Research, vol. 48, no. 18, pp. 8542-8550, 2009.

[9] N. M. N. Lima, L. Z. Liñan, R. M. Filho, M. R. Wolf Maciel, M. Embiruçu, and F. Grácio, "Modeling and predictive control using fuzzy logic: application for a polymerization system," AIChE Journal, vol. 56, no. 4, pp. 965-978, 2010.

[10] Y. Wang, H. Seki, S. Ohyama, K. Akamatsu, M. Ogawa, and M. Ohshima, "Optimal grade transition control for polymerization reactors," Computers and Chemical Engineering, vol. 24, no. 2-7, pp. 1555-1561, 2000.

[11] G. Özkan, S. Özen, S. Erdogan, H. Hapoglu, and M. Alpbaz, "Nonlinear model based control of optimal temperature profiles in polystyrene polymerization reactor," Computers \& Chemical Engineering, vol. 25, pp. 757-763, 2001.

[12] M. J. Park and H. K. Rhee, "Property evaluation and control in a semibatch MMA/MA solution copolymerization reactor," Chemical Engineering Science, vol. 58, no. 3-6, pp. 603-611, 2003. 
[13] S. BenAmor, F. J. Doyle, and R. McFarlane, "Polymer grade transition control using advanced real-time optimization software," Journal of Process Control, vol. 14, no. 4, pp. 349-364, 2004.

[14] G. Özkan, H. Hapoglu, and M. Alpbaz, "Non-linear generalized predictive control of a jacketed well mixed tank as applied to a batch process-a polymerization reaction," Applied Thermal Engineering, vol. 26, pp. 720-726, 2006.

[15] F. Manenti and M. Rovaglio, "Integrated multilevel optimization in large-scale polyethylene terephthalate plants," Industrial and Engineering Chemistry Research, vol. 47, no. 1, pp. 92-104, 2008.

[16] P. Mhaskar, N. H. El-Farra, and P. D. Christofides, "Predictive control of switched nonlinear systems with scheduled mode transitions," IEEE Transactions on Automatic Control, vol. 50, no. 11, pp. 1670-1680, 2005.

[17] P. Mhaskar, N. H. El-Farra, and P. D. Christofides, "Stabilization of nonlinear systems with state and control constraints using Lyapunov-based predictive control," Systems and Control Letters, vol. 55, no. 8, pp. 650-659, 2006.

[18] R. Gandhi and P. Mhaskar, "Safe-parking of nonlinear process systems," Computers and Chemical Engineering, vol. 32, no. 9, pp. 2113-2122, 2008.

[19] C. R. Cutler and B. L. Ramaker, "Dynamic matrix control: a computer control algorithm," in Proceedings of the AIChE 86th National Meeting, Houston, Tex, USA, 1979.

[20] C. E. Garcia and A. M. Morshedi, "Quadratic programming solution of dynamic matrix control (QDMC)," Chemical Engineering Communications, vol. 46, pp. 73-87, 1986.

[21] B. Aufderheide and B. W. Bequette, "Extension of dynamic matrix control to multiple models," Computers and Chemical Engineering, vol. 27, no. 8-9, pp. 1079-1096, 2003.

[22] T. Peterson, E. Hernández, Y. Arkun, and F. J. Schork, "A nonlinear DMC algorithm and its application to a semibatch polymerization reactor," Chemical Engineering Science, vol. 47, no. 4, pp. 737-753, 1992.

[23] F. Gobin, L. C. Zullo, and J. P. Calvet, "Model predictive control of an open-loop unstable train of polymerization reactors," Computers and Chemical Engineering, vol. 18, pp. S525S528, 1994.

[24] A. M. Meziou, P. B. Deshpande, C. Cozewith, N. I. Silverman, and W. G. Morrison, "Dynamic matrix control of an ethylenepropylene-diene polymerization reactor," Industrial and Engineering Chemistry Research, vol. 35, no. 1, pp. 164-168, 1996.

[25] S. Yüce, A. Hasaltun, S. Erdoğan, and M. Alpbaz, "Temperature control of a batch polymerization reactor," Chemical Engineering Research and Design, vol. 77, no. 5, pp. 413-420, 1999.

[26] N. M. N. Lima, "Modeling and predictive hybrid control by fuzzy logic for polymerization processes," M.S. thesis, University of Campinas, Brazil, 2006.

[27] J. A. D. Rodrigues and R. Maciel Filho, "Production optimization with operating constraints for a fed-batch reactor with DMC predictive control," Chemical Engineering Science, vol. 54, no. 13-14, pp. 2745-2751, 1999.

[28] E. C. Vasco de Toledo, "Modelagem, Simulação e Controle de Reatores Catalíticos de Leito Fixo," Ph.D. thesis, University of Campinas, Brazil, 1999.

[29] W. L. Luyben, Process Modeling, Simulation, and Control for Chemical Engineers, McGraw-Hill, New York, NY, USA, 1990.

[30] B. R. Maner and F. J. Doyle, "Polymerization reactor control using autoregressive-plus volterra-based MPC," AIChE Journal, vol. 43, no. 7, pp. 1763-1784, 1997.

[31] N. M. N. Lima, R. M. Filho, M. Embiruçu, and M. R. W. Maciel, "A cognitive approach to develop dynamic models: application to polymerization systems," Journal of Applied Polymer Science, vol. 106, no. 2, pp. 981-992, 2007. 

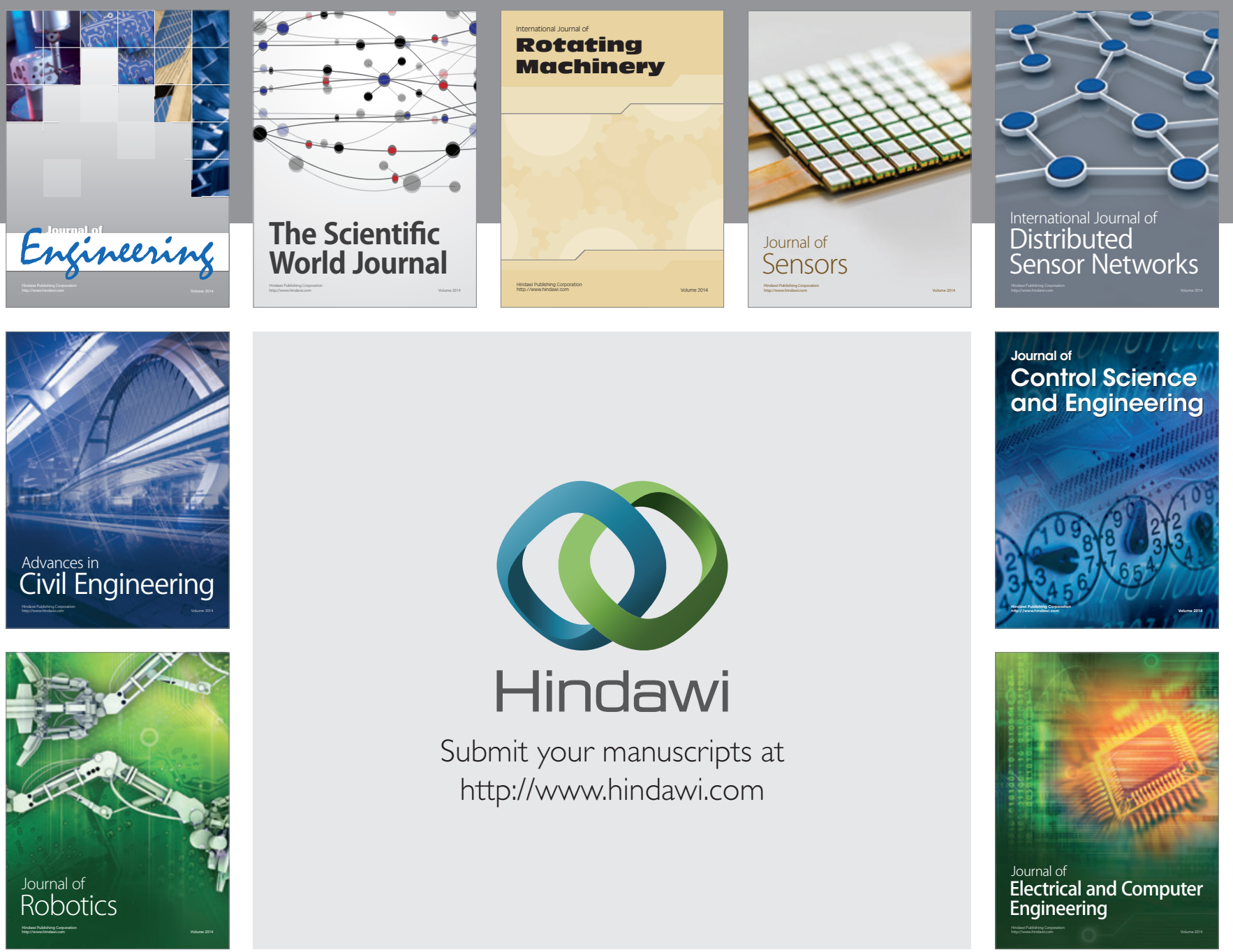

Submit your manuscripts at

http://www.hindawi.com
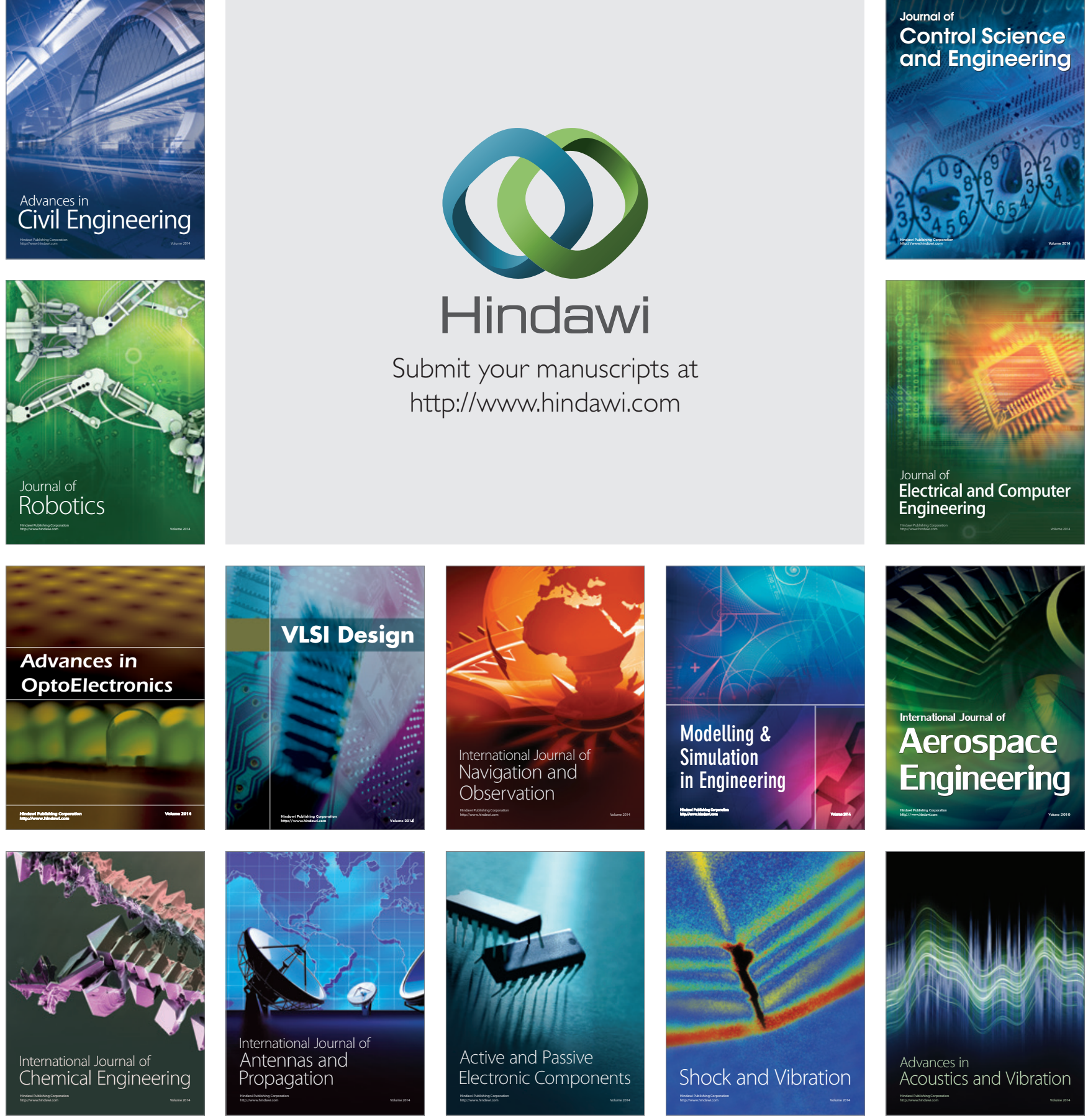